\title{
Corrupción en las empresas y la evasión tributaria del IVA en Colombia: un método alternativo de medición*
}

\section{Corruption in companies and vat tax evasion in Colombia: an alternative method of measurement}

Olga Inés Sierra Rincón** Yamile Ibeth Vargas Noy***

Recibido: 13 de octubre de 2014

Revisado: 14 de enero de 2015

Aprobado: 16 de mayo de 2015

\section{Resumen}

Este trabajo plantea una propuesta metodológica para estimar la evasión tributaria del IVA en Colombia para el año 2010, utilizando la información exógena suministrada por la Dirección de Impuestos y Aduanas Nacionales - DIAN. El método empleado es el potencial teórico, método que contrasta el comportamiento macroeconómico (potencial

* Artículo de investigación presentado para optar al título de Maestría en Estudios y Gestión del Desarrollo de la Facultad de Ciencias Económicas y Sociales de la Universidad de La Salle.

** Profesional en Estadística de la Universidad Nacional, Magíster en Ciencias Estadísticas de la Universidad Nacional. Docente ocasional en la Universidad Nacional. Correo: oisierrar@gmail.com.

*** Profesional en Economía de la Universidad de La Salle, Magíster en Estudio y Gestión de Desarrollo de la Universidad de La Salle. Correo: yivargas08@gmail.com. 
- teórico) frente a las cifras de la administración tributaria (observado). Como teórico se tomó la información que genera el Departamento Nacional de Estadística - DANE, información macroeconómica de las compras y las ventas no exentas de hogares y empresas dentro de las cuentas nacionales proveniente de la Matriz Insumo - Producto (MIP); esta se contrasta con la MIP - DIAN desarrollada desde la información exógena de la DIAN. Las diferencias en los coeficientes permiten identificar las divisiones económicas con mayor evasión en IVA, aportando a la definición de acciones y políticas de fiscalización tributaria en IVA que contribuyan a afrontar la corrupción de las empresas en Colombia.

Palabras clave: corrupción en empresa, evasión tributaria, IVA, método potencialteórico, matrices-insumo-producto.

Glasificación JEL: D22, L22, L60, O14

\section{Abstract}

This paper presents a methodology for estimating tax evasion of VAT in Colombia for 2010, using exogenous information provided by the Directorate of National Taxes and Customs - DIAN. The method used is the theoretical potential, which contrasts the macroeconomic performance (potential - theory) against the figures of the tax administration (observed). The theoretical information was generated by the National Statistics Department took - DANE, macroeconomic shopping information and non - exempt sales of homes and businesses within the national accounts from the Input - Output (MIP). This is contrasted with the MIP - DIAN developed from DIAN exogenous information. The differences in the coefficients allow us to identify the economic divisions with more VAT tax evasion, contributing to the definition of actions and policies of tax examination in VAT that will tackle corruption in Colombian companies.

Keywords: corruption in business, tax evasion, value-added tax (VAT), matrix-input-output

Classification JEL: D22, L22, L60, O14 


\section{Introducción}

La evasión tributaria es una problemática social que afecta el desarrollo de los países. Esto sucede porque se trunca el objetivo principal de los impuestos, a saber, financiar el gasto público, entendido como el total de gastos realizados por el sector público para la adquisición de bienes y servicios, prestación de subsidios y transferencias. Con este recaudo tributario se financian los programas sociales y proyectos estatales de salud, educación, medio ambiente, infraestructura, seguridad y defensa, servicios públicos, entre otros; la evasión tributaria reduce los ingresos del Estado y disminuye su capacidad para atender las necesidades de los ciudadanos.

De acuerdo a los planteamientos expuestos por Yikona, S (2011),

La corrupción de las empresas y la evasión tributaria inciden desfavorablemente en el desarrollo, debido a que el dinero obtenido ilícitamente no se gasta en inversiones productivas que puedan tener un efecto multiplicador en la economía y beneficiar a la gran mayoría de la población, en lugar de solo a unos pocos elegidos. La evasión tributaria afecta la competitividad del país al poner en desventaja aquellos empresarios que deciden cumplir con sus obligaciones tributarias, y en ocasiones llevando a la quiebra y cierre de las empresas.

El objetivo principal de la presente investigación es desarrollar una propuesta metodológica comparativa para estimar la evasión tributaria del IVA para el año 2010, a partir de la información exógena de la DIAN, como aporte a la definición de políticas de fiscalización que permitan enfrentar la corrupción de las empresas en Colombia (Cotte y Lancheros, 2015). Para tal fin, se ve la necesidad de proponer métodos alternativos de medición para la evasión del IVA, con los cuales se puedan develar patrones, tendencias y comportamientos no capturados por los métodos actuales, y visibilizar nuevas formas de la evasión en los sectores económicos, los subsectores y las actividades económicas. El presente estudio utiliza la información exógena de la DIAN disponible para el año 2010, la cual, hasta el momento, no había sido utilizada para este fin.

Esta investigación cuantitativa mide el grado de correlación y discrepancia entre la información de compras y ventas de la DIAN y la información de cuentas nacionales del DANE. Esta propuesta de estimación usa como técnica de estimación el Método del Potencial Teórico, y se basa en el contraste del flujo de compras y ventas que estima el DANE (potencial teórico), y la información de compras y ventas capturada en la información exógena de la DIAN (recaudado esperado). Tradicionalmente, la información del DANE se aproxima a la información de declaraciones de IVA de la DIAN, lo que implica moldear las estimaciones según las normas y tarifas de IVA del Estatuto Tributario vigente al momento de la estimación.

Macías, Agudelo y López (2007) presentan una aproximación de las investigaciones en evasión, para profundizar en el tema. En su investigación se identifican las motivaciones 
que conducen a los contribuyentes a asumir una conducta evasora; realizan estimaciones que destacan la divergencia en los resultados de las variables y los métodos utilizados para medir la evasión fiscal, llegando a la conclusión que los métodos más utilizados desde la academia son métodos indirectos, que si bien dan un panorama más o menos preciso de la evasión, no alcanzan a llegar a un nivel de detalle que permita diseñar programas para combatirla de manera efectiva. Otra alternativa sería concentrarse en diseñar mecanismos de cumplimiento voluntario en los contribuyentes, con herramientas administrativas de un nivel técnico menos complejo.

El aporte del presente trabajo radica en establecer una metodología alternativa para la medición de la evasión del IVA en Colombia, mediante: i) El aprovechamiento de la información exógena de la DIAN para realizar estimaciones macroeconómicas; y ii) Llevando los datos DIAN a los datos DANE, eliminado aspectos normativos y tarifarios (cambiantes) que puedan incidir desfavorablemente en las estimaciones de evasión tributaria o en su comparabilidad interanual.

El artículo se organiza de la siguiente manera: el presente apartado corresponde a la introducción; la segunda parte muestra el enfoque teórico de la investigación, basado en el Método del Potencial Teórico. La tercera parte muestra el análisis de la consistencia entre la información del DANE y DIAN. En la cuarta se muestra la comparación de las matrices de utilización DIAN con la de oferta DANE, para identificar de manera indirecta los nichos de evasión en IVA. Y en la última parte se muestran los resultados y hallazgos obtenidos, con las propuestas de líneas de acción para el control de la evasión en Colombia, y las conclusiones.

\section{Marco teórico - conceptual}

En la Convención de las Naciones Unidas contra la Corrupción de diciembre de 2003, Kofi Annan señaló que la corrupción perjudica desproporcionadamente a los pobres al desviar fondos destinados en principio para el desarrollo, debilitar la capacidad de los gobiernos para prestar servicios básicos, y alimentar la desigualdad y la injusticia.

Una reseña del concepto de corrupción en lo público la construye Morales (2009, p. 6) a partir de la definición dada por la agencia de Transparency International: "[...] corrupción se define como aquel acto en que se produce un abuso de la función pública para beneficios". Morales se refiere a Treisman (2000), quien entiende la corrupción como "[...] el mal uso de la función pública para obtener ganancias personales". Además se menciona que La Palombara (1994) concreta a la corrupción como:

[...] acto realizado por servidores públicos (electos o designados) en beneficio personal o de personas cercanas a ellos, lo cual manifiesta una conducta desviada de sus funciones institucionales. Tal acto requiere una transacción, la que no necesariamente encuentra como contraparte a otro agente estatal, sino a agentes de la sociedad civil que pueden ser empresarios, 
sindicatos, grupos de presión o partidos políticos [...] Además, la corrupción puede volverse persistente a pesar de las reformas anticorrupción, llegando a transformarse en una norma social.

Desde esta perspectiva, la corrupción se refiere al aprovechamiento de las condiciones de poder, que inciden en el beneficio de unos, quienes en el caso de los asuntos públicos pueden conformar sinergias entre los funcionarios de las instituciones y las empresas. Son diversos los análisis realizados y las perspectivas empleadas para deliberar sobre el tema (Cotte, 2014); en el análisis de la corrupción de las empresas y su tipificación en la evasión tributaria, se encuentran los trabajos de Garzón (1996), quien realiza un abordaje detallado y sobre el tema, que permite entender el fenómeno de corrupción como el marco en el cual opera la evasión tributaria. Imam y Jacobs (2007) asumen el concepto de corrupción de empresas como equivalente al fenómeno de evasión tributaria. Según Garzón (1996, p. 2), "El concepto de corrupción está lógicamente vinculado con el de sistema normativo. No es posible hablar de corrupción sin hacer referencia simultáneamente al marco normativo dentro del cual se produce el acto o la actividad calificada de corrupta".

Para el caso colombiano, el contenido del Estatuto Tributario expresa las obligaciones, deberes y responsabilidades de los sujetos pasivos y contribuyentes del impuesto sobre las ventas - IVA, que, según el autor, son deberes adquiridos, "[...] promesas o aceptación expresa o tácita de una determinada posición en una práctica social, no cuesta admitir que la corrupción implica siempre un acto de deslealtad o hasta de traición con respecto al sistema normativo relevante". Tomando como referencia Garzón, Imam y Jacobs (2007), construimos la definición de corrupción que se empleará en este estudio: La corrupción es un fenómeno social, que opera en lo público, y consiste en el abuso, aprovechamiento o manipulación del poder, con el propósito de beneficiar a las empresas en una reducción u omisión en sus obligaciones y responsabilidades tributarias del IVA; la corrupción implica la transgresión del Estatuto Tributario y sus Decretos o Resoluciones reglamentarias.

Garzón (1996), en su concepto de corrupción, se refiere a la evasión fiscal o tributaria como una forma de violar la norma, que consiste en no pagar de forma consciente y voluntaria algún impuesto establecido por la Ley. La actividad gravada por el impuesto es realizada y ocultada al conocimiento de las autoridades tributarias y, para ello, utiliza métodos ilícitos para reducir la cantidad a pagar. La evasión es ilegal y perseguida por la Ley como delito penal; las formas de evasión se pueden mostrar como: i) Ocultamiento de ingresos; ii) Aumento ilícito de los gastos deducibles: y iii) Adquisición de subvenciones injustificadas. Las siguientes citas nos permitirán acercarnos a la definición más concreta de "evasión tributaria":

La evasión tributaria es el conjunto de acciones u omisiones orientadas a reducir parcial o totalmente el monto de impuestos que legalmente le corresponde aportar a un contribuyente. Estas prácticas van desde el ocultamiento total del sujeto del tributo, que trata de hacerse invisible ante la administración tributaria, hasta la falsificación de información que sirve de 
base para determinar la contribución. Cuanto más compleja es la legislación mayor será la probabilidad de hallar vacíos legales que permiten reducir la tributación a cargo de los contribuyentes sin que dicha práctica pueda calificarse como ilegal. En estos casos se habla de elusión de impuestos que tiene en común con la evasión tributaria el efecto de reducir el monto de los tributos a cargo del contribuyente, solo que en tal situación la disminución se produce en un claro-oscuro de la legislación, que impide calificar dicha práctica como ilegal. (Ávila y Cruz, 2007, p. 6)

La evasión fiscal o tributaria es toda eliminación o disminución de un monto tributario producida dentro del ámbito de un país por parte de quienes están jurídicamente obligados a abonarlo y que logra tal resultado mediante conductas fraudulentas u omisivas violatorias de disposiciones legales. (Villegas, 2002)

Continúa Villegas (2002), haciendo referencia a Toro (1993): "En términos generales la evasión de impuestos puede definirse como el acto de no declarar y no pagar un impuesto en contradicción con el espíritu de la ley, que tenía por objeto de gravar una determinada actividad $[\ldots]$ ".

Por evasión fiscal debe entenderse aquella porción de los tributos que no llega a las arcas fiscales por múltiples motivos, bien sea por el alto tamaño de la economía informal o por aquella parte de la economía formal omitida en las declaraciones [...] las conductas evasoras se manifiestan en acciones concretas como no presentar las declaraciones tributarias, incurrir en errores aritméticos generando un menor saldo a pagar, un mayor saldo a favor y omitiendo las sanciones; correcciones sucesivas de las declaraciones; omitir ingresos y, finalmente, incluir costos, descuentos, deducciones o impuestos descontables inexistentes. (Cardona, Agudelo y López, 2007)

Para este trabajo, se entenderá "evasión tributaria" como una forma de corrupción, siendo un fenómeno social complejo y difícil que aprovecha y usa a su favor el fraude o la violación de la legislación tributaria, y que no solo implica una pérdida de ingresos fiscales con su efecto consiguiente en la prestación de servicios públicos, sino que también compromete los recursos para el desarrollo. La evasión desencadena en la distorsión en el sistema tributario y en una menor capacidad del Estado para responder a las necesidades de la nación.

\section{Revisión de literatura}

Steiner y Soto (1998) establecen los métodos para medir la evasión y basan su investigación en el método de identificación de brechas de ingreso, que los lleva a resultados que identifican que las medidas adoptadas en los últimos años en Colombia para mediar la evasión del impuesto de renta han sido efectivas y han favorecido el cumplimiento del impuesto. Entre estas medidas se destacan la unificación de tasas para sociedades limitadas y anónimas, la unificación de la tarifa de sociedades con la marginalidad máxima para personas naturales, la simplificación de los formularios de impuestos, la 
autorización del pago en entidades bancarias, la generación de mecanismos de retenciones y la creación de unidades tributarias más amplias.

Ávila y Cruz (2007) presentan la magnitud de la evasión en el impuesto al valor agregado en Colombia para el período 1998 - 2006, desarrollando un análisis empírico que se concentra en la aplicación y adaptación para el caso colombiano de un método de estimación, basado en el contraste entre el recaudo potencial obtenido a partir de las Cuentas Nacionales y el recaudo efectivamente observado. El método de estimación empleado permitió estimar que la tasa de evasión del IVA en Colombia fue del $23.5 \%$ para el año 2006. Este porcentaje de evasión redujo en $\$ 6.6$ billones $-2 \%$ del PIB- los ingresos tributarios del año 2006. Según este estudio, la evasión presentó una tasa decreciente durante los últimos años, pasando del $31.5 \%$ observado en 1998 al $23.5 \%$ en el 2006. Adicionalmente, concluyen que si cada año se hubieran mantenido las tasas de evasión del año 1998 el fisco nacional hubiera perdido alrededor de $0.59 \%$ del PIB -a precios de 2006 equivaldría a $\$ 2.3$ billones-.

Las reformas tributarias de los años 2002 y 2003, particularmente la primera, permitieron incrementar la cobertura de la base gravable del IVA. Este impuesto pasó de gravar el $42.7 \%$ de la demanda a cubrir el $56 \%$ del total de bienes y servicios transados en la economía colombiana. En términos de la canasta familiar, el IVA recae sobre 117 productos de los 176 que la integran y afectan al $43 \%$ del valor de dicha canasta. Reducciones adicionales en la evasión del IVA están vinculadas a la reforma tributaria, que establece máximo una o dos tarifas y contempla la ampliación de la base imponible y la reducción de la tarifa general.

Clavijo (2007) indica en su artículo que solo a través de una mayor transparencia y equidad tributaria será posible equilibrar la frágil estructura de recaudos que se tiene hoy en día. Adicionalmente, con la reforma tributaria de finales de 2006 se logró reducir las elevadas tasas de impto renta, pero se fracasó en eliminar múltiples exenciones y volvió permanente el impuesto a las transacciones financieras y semipermanente el impuesto a la riqueza. Clavijo (2007) concluye que esta situación llevará al Estado colombiano a adoptar soluciones de fondo durante los años 2007 - 2010, que necesariamente implicarán una elevación de la tasa general del IVA del $16 \%$ al $17 \%$.

\section{Planteamiento metodológico}

Según De Luis (2009, p. 112):

Medir la evasión no es una tarea fácil. Por razones obvias, preguntar directamente es la forma menos confiable para observar esta variable: los agentes involucrados difícilmente revelarán cuánto impuesto han dejado de pagar en un período dado, aun cuando se les garantice total anonimato, en este sentido, los métodos de medición deben seguir vías indirectas para obtener resultados más confiables. 
Para el caso estudiado se establecen tres enfoques para las estimaciones de evasión tributaria: i) Un método de estimación indirecto, llamado el potencial teórico, que recurre a variables relacionadas para aproximar la recaudación que se obtendría si todos los contribuyentes pagasen sus impuestos, la que luego puede ser comparada con la recaudación efectiva para determinar evasión; ii) Un segundo método de carácter muestral utiliza el aparato de la administración tributaria para detectar el incumplimiento, fiscalizando una muestra representativa de contribuyentes y extendiendo luego sus resultados al universo de ellos; y iii) El tercer enfoque hace uso de las técnicas econométricas y las encuestas de percepción para medir la evasión tributaria.

Tabla 1. Enfoques de medición de la evasión

\section{Enfoque indirecto}

Basado en Cuentas Nacionales. Basado en Encuestas de Hogares. Usando transacciones monetarias o demanda de dinero. Usando la tabla insumoproducto.

\section{Enfoque directo}

Auditorías especiales.

Uso de datos de las auditorías ordinarias.

Uso de datos de amnistías, campañas de recaudo y fraccionamientos.
Enfoque econométrico

Encuestas de percepción. Experimentos controlados (campo y laboratorio). El "punto fijo". Modelos econométricos.

Fuente: elaboración propia basada en La economía de los ingresos tributarios. Un manual de estimaciones tributarias. CEPAL - Serie Manuales No. 62.

Dentro de las posibilidades metodológicas para este trabajo se hace uso del método de estimación indirecta, conocido como el potencial teórico. En esta técnica de estimación de la evasión tributaria del IVA se hace uso del contraste de dos fuentes de información: Por un lado, la fuente de información da cuenta del comportamiento macroeconómico de las compras y las ventas (potencial), contra una segunda que observa desde la entidad tributaria esta misma dinámica (recaudado). Esta técnica considera el principio sobre el cual se genera el impuesto del IVA, que son las transacciones de compra y venta de bienes o servicios gravados con el impuesto. Para establecer el flujo de compras y ventas se toma como información referente la generada por el DANE, información macroeconómica de las compras y las ventas no exentas de hogares y empresas, que se conoce dentro de las cuentas nacionales como la Matriz Insumo - Producto (MIP), y sus adyacentes, el vector de oferta y el vector de utilización. Metodológicamente, se propone que la información para el contraste sea aquella que proviene de los sujetos pasivos del impuesto de IVA, contenida en la información exógena de la DIAN (también conocida como la información de medios magnéticos).

Con los cálculos del $D A N E-M I P$ y los cálculos propuestos $D I A \mathcal{N}-M I P$, se presenta una comparación a nivel de divisiones económicas de los coeficientes de las matrices, la cual nos permite identificar las que presentan las mayores diferencias y, así, las que revelan la evasión. 
La estimación de la Matriz Insumo Producto - MIP desde la información exógena de la DIAN parte del cálculo de la matriz de coeficientes técnicos, el vector fila de compras y la vector columna de ventas. En la elaboración de los cálculos se procede de la siguiente manera:

Tabla 2. Procedimiento metodológico de cálculo MIP - DIAN

\section{Paso}

\section{Procesamiento}

Se aplica la homologación de la división DANE con el nivel de agregación de la Clasificación Industrial Internacional Uniforme de todas las actividades económicas (CIIU) de la DIAN

1. (según la tabla del anexo 3).

El universo de estudio con la información de la DIAN está conformado por informante e informado, registros del formato de ventas 1007 y se restringe a aquellos que estén inscritos en el RUT, con CIIU válido, con fecha de corte del 31 de diciembre del 2010.

En estimación de DIAN-MIP, el cálculo de los coeficientes técnicos (o multiplicadores) utiliza como fuente la información recolectada en el formato de información de medios magnéticos, La Resolución de Medios Magnéticos está compuesta de varios capítulos, de los cuales el

2. F1001 da cuenta de las compras de los obligados a reportar esta información, y F1007 da cuenta de las ventas de los obligados a reportar esta información. Con esta consideración se tomaron como insumo para el presente trabajo. El F1007 es insumo para el cálculo de los coeficientes técnicos de la matriz donde el informante es el ofertante (vendedor) y el informado es el demandante (comprador).

Se calculan los coeficientes técnicos de la matriz técnica (A). Los coeficientes técnicos son relaciones entre las compras de la división $i$ a la división $j$, y la razón con el total de compras

3. la división $j$.

$$
a_{i j}=\frac{c_{i j}}{C_{j}}
$$

Se calcula la fila marginal de la matriz técnica (A), cuyos totales se denominan como vector ROW $(\mathrm{R})$ y corresponde a la suma de todas las compras realizadas por la división i. Da cuenta de la suma por división de totas las compras del informado.

4.

$$
R=\left[\begin{array}{c}
r_{1} \\
\vdots \\
r_{i} \\
\vdots \\
r_{I}
\end{array}\right] \text {, donde } r_{i}=\sum_{j} c_{i j}
$$

Se calcula la columna marginal de la matriz técnica (A), cuyos totales se denominan como vector COL (S) y consigna la suma de todas las ventas realizadas por la división j. Es decir, da cuenta de la suma por división de totas las ventas del informante.

5.

$$
S^{\prime}=\left[\begin{array}{c}
s_{1} \\
\vdots \\
s_{j} \\
\vdots
\end{array}\right] \text {,donde } s_{j}=\sum_{i} c_{i j}
$$




\begin{tabular}{cl} 
Paso & \multicolumn{1}{c}{ Procesamiento } \\
\hline 6 Para identificar las divisiones evasoras se identifican los vectores estadísticamente más corre- \\
lacionados o asociados de las combinaciones oferta, utilización, DANE-DIAN. Para tal fin se \\
utilizan como indicadores los coeficientes de correlación de Pearson, Spearman y Kendall. \\
La comparación de los vectores se realiza sobre la participación porcentual de los vectores co- \\
lumna Utilización $(\mathrm{S})$ y Oferta $(\mathrm{R})$. Debido a que es un modelo que busca identificar la evasión \\
desde las diferencias que resultan de las siguientes hipótesis estadísticas: i) Utilización $(\mathrm{S})_{\text {DIAN }}=$ \\
Utilización $(\mathrm{S})_{\text {DANE }}$ y ii) Oferta $(\mathrm{R})_{\text {DIAN }}=$ Oferta $(\mathrm{R})_{\text {DANE }}$, se verifica desde un modelo de calibra- \\
ción de tipo lineal simple $($ ver anexo 4) que contiene los cálculos del modelo y validación de \\
supuestos, desarrollados en la herramienta SPSS.
\end{tabular}

Fuente: elaboración propia basada en Lora (2008, p. 317 - 330).

Para las diferentes estimaciones se enuncian los siguientes supuestos y restricciones económicas:

i) Homogeneidad sectorial: cada insumo es suministrado por un solo sector o división. Esto implica que cada uno de los sectores tiene una producción primaria o característica, pero no secundaria.

ii) Invariancia de los precios relativos: insumos o productos iguales tienen precios de valoración iguales para todos los productores.

iii) Hipótesis de proporcionalidad: la cantidad de insumos varía en la misma proporción que varía la producción. Esto implica que los factores e insumos no son determinados por los precios relativos.

iv) Hipótesis de aditivita: el efecto total sobre la producción de varios sectores es igual a la sumatoria de la producción de los sectores.

v) No se consideran las transacciones por importaciones o exportaciones.

vi) Es de carácter trasversal, es decir, no considera la demanda (compras) y oferta (ventas) de años anteriores o posteriores.

vii) Se supone que la cadena de producción de un paso (informante-informado).

\section{Discusión de resultados}

\subsection{Análisis de consistencia de la información DANE y DIAN}

Este análisis se desarrolla al comparar los vectores $\mathrm{S}$ de utilización (ventas) y $\mathrm{R}$ de oferta (compras) construidos desde la información de cada una de las entidades. Se espera que estos dos vectores estén estadísticamente correlacionados, lo que permite ver consistencia en la información global de transacciones, bajo la premisa de que toda compra resulta de una venta. 


\section{Contraste información DIAN}

Se verifica la consistencia en la información obtenida por la DIAN, comparando la estimación de los vectores Utilización (S) y Oferta $(\mathrm{R})$. Los resultados muestran que los vectores $\mathrm{R}$ y $\mathrm{S}$ en monto de transacciones no difieren significativamente; sin embargo, la mayoría de los informantes tienden a mostrar más compras que ventas, a pesar que la información proviene de un mismo conjunto de informantes. Estadísticamente, los dos vectores son muy similares en su información, con un grado de correlación lineal del $90 \%$ (ver gráfico 1 ).

\section{Gráfico 1. Comparación Oferta - Utilización DIAN}

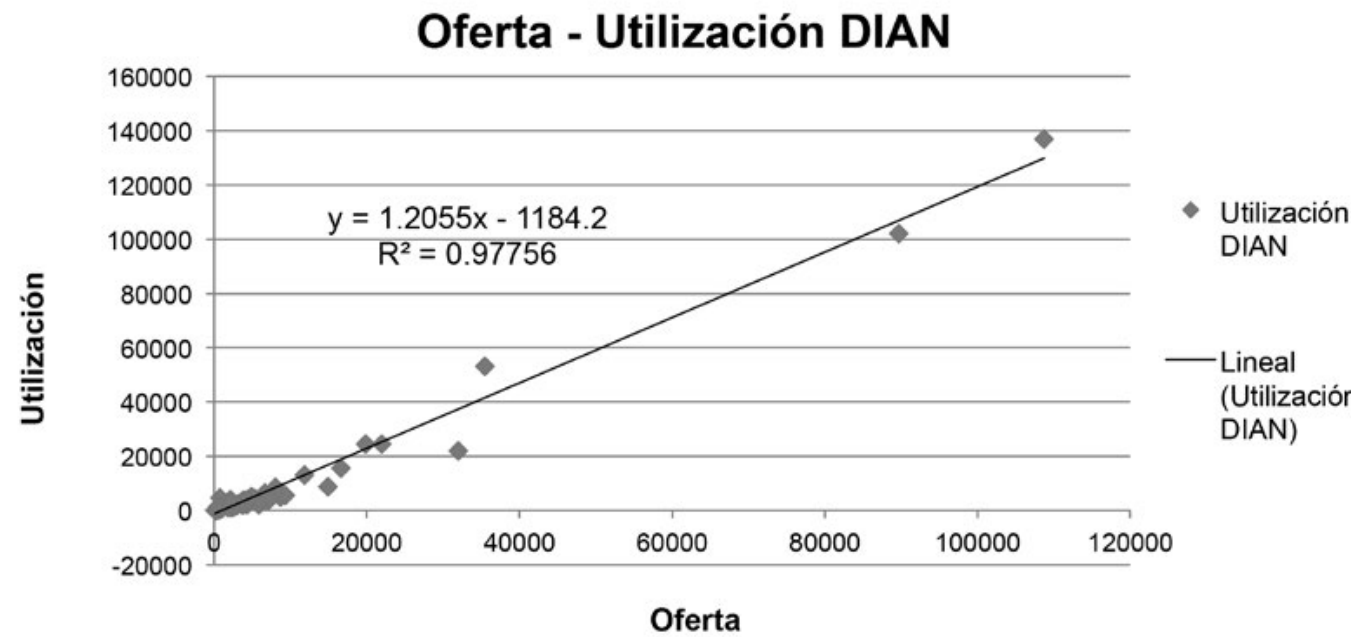

Fuente: vector DIAN cálculos propios información del Formatos 1001 y 1007 año 2010.

Lo anterior nos permite señalar que la información de compras y ventas que tiene la DIAN está estrechamente vinculada y el uso de una u otra es indiferente debido a que no proveen información diferente sobre los procesos de transacción entre divisiones económicas; sin embargo, se privilegia al formato de 1007, que da cuenta de las ventas de los informantes y con una cantidad superior de registros que el formato 1001 .

\section{Contraste información DANE}

Se analizan las consistencias en las estimaciones del DANE. Para tal fin se compara la estimación de los vectores Utilización ( $\mathrm{S})$ y Oferta $(\mathrm{R})$, vectores tomados de la información suministrada por el DANE en el apartado de Cuentas Nacionales. 
Gráfico 2. Comparación Oferta-Utilización DANE

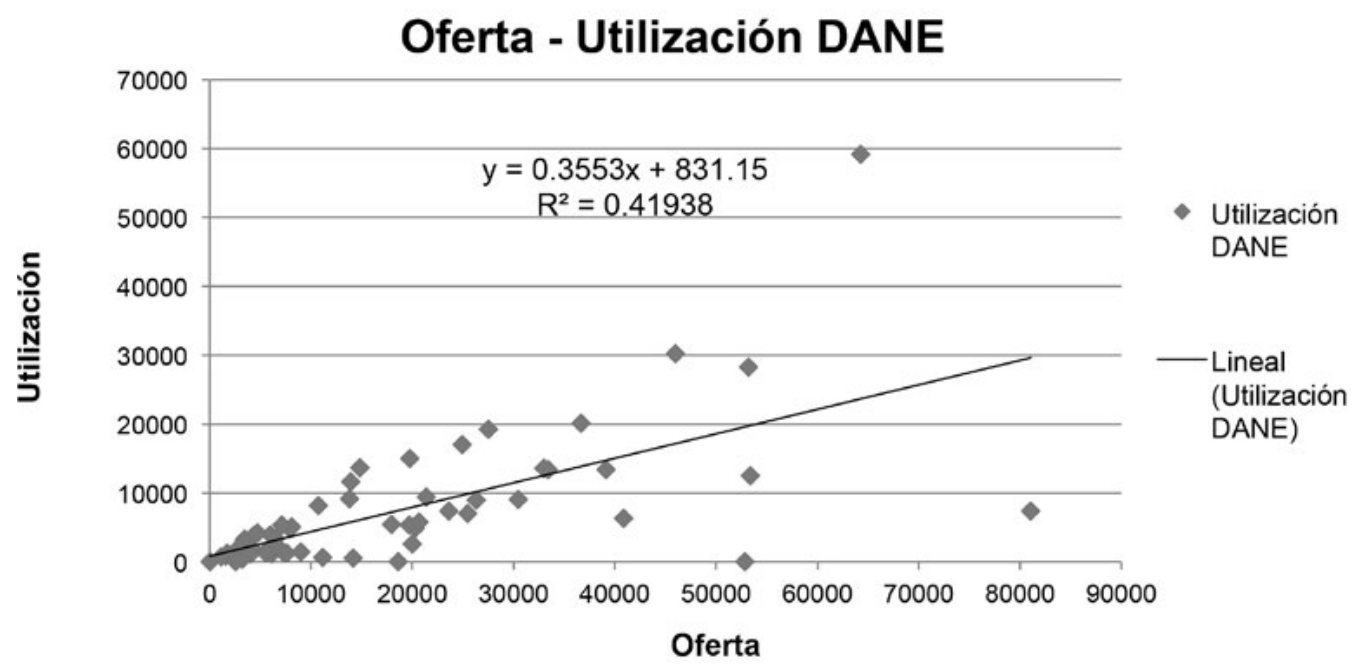

Fuente: vector DANE tomado de la página WEB DANE - Cuentas Nacionales-Anuales Matriz de Oferta 2010.

El gráfico 2 muestra que la oferta y la utilización estimada por el DANE presenta diferencias, con una correlación lineal de tan solo $41 \%$, al igual que para la estimación DIAN es mayor el total de oferta al de utilización. Estadísticamente, la oferta y utilización del DANE no son equivalentes.

\subsection{Análisis de correlación DIAN - DANE}

La metodología de estimación del teórico potencial se basa en el contraste de información; por lo tanto, técnicas como el análisis de correlación nos permiten identificar relaciones entre los vectores que van más allá de lo numérico.

Se obtienen y analizan los coeficientes de Pearson para los vectores de DIAN versus DANE, encontrando que el coeficiente de Pearson de los vectores de oferta DIAN y oferta DANE es del 30 \% y el coeficiente de Pearson de los vectores de la utilización DIAN y utilización DANE es del $20 \%$ (ver tabla 3).

Del análisis de correlación se establece que la relación entre los vectores DIAN - DANE no es directamente lineal. En particular, los vectores de utilización tiene una correlación de Pearson de tan solo el 20 \%. Los coeficientes de correlación no paramétrica evidencian que existe asociación: en la tabla 4 de correlaciones se muestra que el vector $\mathrm{S}$ de Utilización de la DIAN es estadísticamente más cercano a la información del DAN, con una correlación de Spearman del 70 \%. Para la comparación de las matrices se propone 
contrastar el vector de utilización DIAN con el vector de oferta DANE, para identificar de manera indirecta los nichos de evasión en IVA por división económica.

Como parte de los anexos al documento se presentan las comparaciones de los vectores de utilización DIAN-DANE y de oferta DIAN-DANE, que aunque no son la combinación óptima permiten sustentar los hallazgos.

Tabla 3. Correlación paramétrica Pearson vectores DIAN-DANE

\begin{tabular}{|c|c|c|c|c|}
\hline & DIAN S & DIAN R & DANE $S$ & DANE $R$ \\
\hline DIAN S & 1 &, $989 * *$ & 209 & ,254 \\
\hline DIAN R & & 1 & ,318* &, $302 *$ \\
\hline DANE S & & & 1 &, $648 * *$ \\
\hline DANE R & & & & 1 \\
\hline
\end{tabular}

Fuente: cálculos propios. Vector DIAN cálculos propios basados en la información F1007 año 2010. Vector DANE tomado del DANE - Cuentas Nacionales-Anuales Matrices de Oferta y Utilización 2010.

Tabla 4. Correlación no paramétrica vectores DIAN - DANE

\begin{tabular}{|c|c|c|c|c|c|}
\hline \multicolumn{2}{|c|}{$\begin{array}{l}\text { GORRELAGIONES NO } \\
\text { PARAMÉTRIGAS }\end{array}$} & DIAN- R & DIAN -S & DANE- $\mathbf{R}$ & DANE- S \\
\hline \multirow{4}{*}{ Tau b de Kendall } & DIAN- R & 1,000 &, $793 * *$ &, $525^{* *}$ &, $442 * *$ \\
\hline & DIAN $-\mathrm{S}$ & & 1,000 &, $556 * *$ &, $461 * *$ \\
\hline & DANE- S & & & 1,000 &, $544 * *$ \\
\hline & DANE- R & & & & 1,000 \\
\hline \multirow{4}{*}{ Rho de Spearman } & DIAN- R & 1,000 &, $916 * *$ &, $656 * *$ &, $560 * *$ \\
\hline & DIAN -S & & &, $701 * *$ &, $596 * *$ \\
\hline & DANE- R & & & 1,000 &, $705^{* *}$ \\
\hline & DANE- S & & & & 1,000 \\
\hline \multicolumn{6}{|c|}{ **La correlación es significativa al nivel 0,01 (bilateral). } \\
\hline
\end{tabular}

\subsection{Implementación del método potencial teórico}

\section{Comparación de los vectores de utilización DIAN-oferta DANE}

En el gráfico 3 se identifica que los valores de oferta del DANE están por encima de los valores calculados con la información de la DIAN. Estas diferencias permiten evidenciar que en el vector de oferta DANE la división de comercio - No. 43 no presenta valor de producción (ver tabla 6), mostrando una diferencia de 137.026 miles de millones de 
pesos, con respecto al vector de utilización de la DIAN. Así mismo, en aquellas divisiones cuya descripción es servicios, encontramos que los valores de utilización DIAN son mayores a los valores de oferta DANE, esto debido a que la producción se define como un conjunto de productos, dejando los servicios fuera de las cuentas. Por último, la oferta total calculada por el DANE supera a la utilización calculada para la DIAN, lo que muestra que no todo lo que es resultado del proceso productivo del país resulta en una transacción de compra-venta interna, explicado por los resultados de las divisiones relacionadas en minería e hidrocarburos (No. 6, 7, 8 y 9).

De acuerdo con los resultados se encuentra que DIAN y DANE no tienen valores absolutos cercanos (ver anexo 1). También se hace la comparación de los valores relativos de la participación de cada división (ver gráfico 3), el cual contiene en el eje X la participación de las divisiones en la utilidad total con los cálculos DIAN, y en el eje Y la participación de las divisiones en la oferta total con los datos del DANE. Se espera que si estas dos metodologías miden de manera equivalente la participación de la división j en el total de la utilización, un modelo de regresión que pase por el origen será de buen ajuste. Bajo esta premisa podemos decir que aquellos puntos que están más cercanos a la curva del gráfico 3 corresponden a las divisiones cuya utilización DIAN se aproxima estadísticamente a la oferta DANE, mientras la mayores discrepancias son en los puntos alejados de la curva, que para nuestro caso están indicando los nichos de evasión de IVA.

Gráfico 3. Comparación Utilización DIAN-Oferta DANE

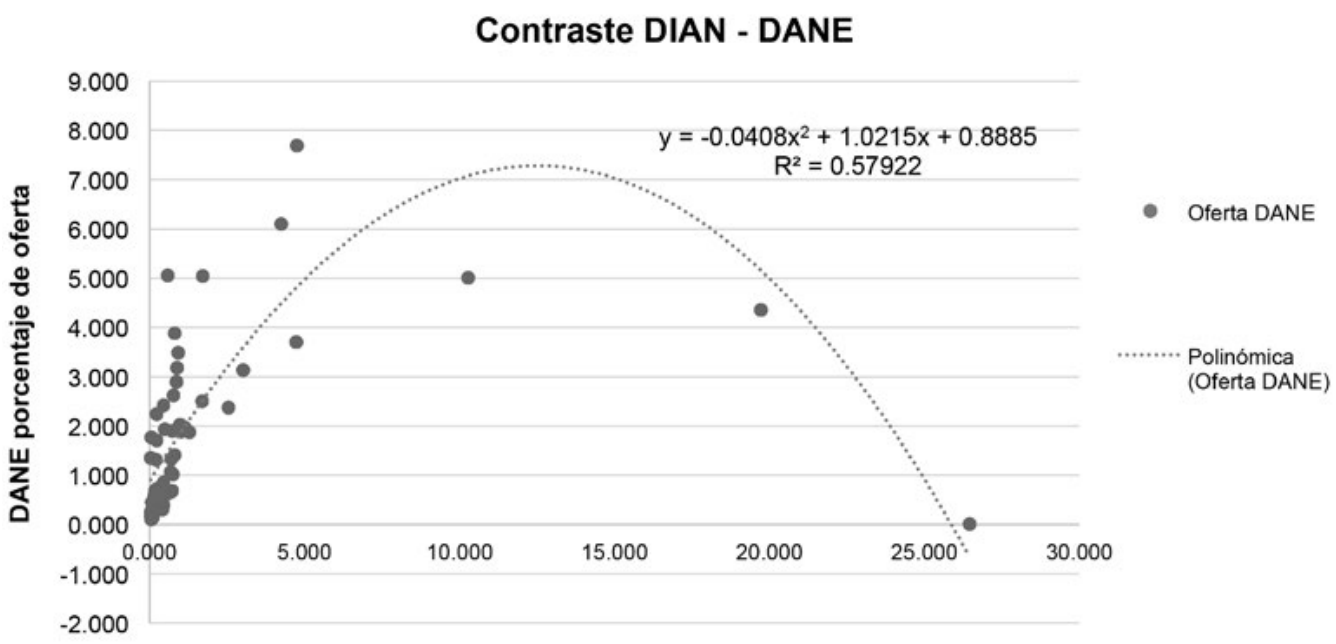

DIAN Porcentaje de utilización

Fuente: cálculos propios. Vector DIAN cálculos propios basados en la información F1007 año 2010. Vector DANE tomado del DANE - Cuentas Nacionales-Anuales Matrices de Oferta y Utilización 2010. 
La tabla 5 presenta las divisiones económicas con menores diferencias en la información DANE-DIAN, a saber, productos alimenticios, servicios complementarios y auxiliares al transporte, gas domiciliario, productos de la pesca, la acuicultura y servicios relacionados, y servicios de transporte por vía acuática. Estas son las divisiones donde, desde esta metodología, no se evidencia evasión tributaria en IVA, debido a la cercanía de los coeficientes. De manera contraria, la tabla 6 muestra las divisiones con mayores diferencias, es decir, las divisiones que presentan evasión del IVA. En ellas, se destacan: servicios de intermediación financiera, sustancias y productos químicos, servicios de alojamiento, suministro de comidas y bebidas, trabajos de construcción, construcción de obras civiles y servicios de arrendamiento de equipo con operario. Estas son divisiones que se identifican desde otras metodologías como evasoras del IVA, lo que le da consistencia a los resultados de la metodología propuesta.

Tabla 5. Divisiones con participación similar Utilización DIAN-Oferta DANE

\begin{tabular}{|c|l|c|c|}
\hline División & \multicolumn{1}{|c|}{ Descripción división } & Utilización DIAN \% & Oferta DANE \% \\
\hline 17 & Productos alimenticios n.c.p & 0,680 & 0,658 \\
\hline 49 & $\begin{array}{l}\text { Servicios complementarios y auxiliares al } \\
\text { transporte }\end{array}$ & 0,723 & 0,676 \\
\hline 39 & Gas domiciliario & 0,434 & 0,385 \\
\hline 5 & $\begin{array}{l}\text { Productos de la pesca, la acuicultura y } \\
\text { servicios relacionados }\end{array}$ & 0,094 & 0,150 \\
\hline 47 & Servicios de transporte por vía acuática & 0,037 & 0,102 \\
\hline
\end{tabular}

Fuente: cálculos propios. Vector DIAN cálculos propios basados en la información F1007 año 2010. Vector DANE tomado del DANE - Guentas Nacionales-Anuales Matrices de Oferta y Utilización 2010.

Tabla 6. Divisiones con mayores diferencias Utilización DIAN-Oferta DANE

\begin{tabular}{|c|l|c|c|}
\hline División & \multicolumn{1}{|c|}{ Descripción división } & Utilización DIAN \% & Oferta DANE \% \\
\hline 43 & Comercio & 26,452 & 0,000 \\
\hline 51 & $\begin{array}{l}\text { Servicios de intermediación financiera, } \\
\text { de seguros y servicios conexos }\end{array}$ & 19,715 & 4,363 \\
\hline 54 & $\begin{array}{l}\text { Administración pública y defensa; } \\
\text { dirección, administración y control del } \\
\text { sistema de seguridad social }\end{array}$ & 10,287 & 5,014 \\
\hline 52 & $\begin{array}{l}\text { Servicios inmobiliarios y de alquiler de } \\
\text { vivienda }\end{array}$ & 0,565 & 5,062 \\
\hline 28 & Sustancias y productos químicos & 1,700 & 5,048 \\
\hline
\end{tabular}




\begin{tabular}{|c|l|c|c|}
\hline División & \multicolumn{1}{|c}{ Descripción división } & Utilización DIAN \% & Oferta DANE \% \\
\hline 45 & $\begin{array}{l}\text { Servicios de alojamiento, suministro de } \\
\text { comidas y bebidas }\end{array}$ & 0,790 & 3,879 \\
\hline \multirow{2}{*}{41 y 42} & $\begin{array}{l}\text { Trabajos de construcción, construcción } \\
\text { de obras civiles y servicios de } \\
\text { arrendamiento de equipo con operario }\end{array}$ & 4,751 & 7,695 \\
\hline 27 & $\begin{array}{l}\text { Productos de la refinación del petróleo; } \\
\text { combustible nuclear }\end{array}$ & 0,910 & 3,480 \\
\hline 2 & Otros productos agrícolas & 0,867 & 3,168 \\
\hline 57 & Servicios sociales y de salud de mercado & 0,853 & 2,888 \\
\hline 33 & Otra maquinaria y suministro eléctrico & 0,212 & 2,241 \\
\hline
\end{tabular}

Fuente: cálculos propios. Vector DIAN cálculos propios basados en la información F1007 año 2010. Vector DANE tomado del DANE - Guentas Nacionales-Anuales Matrices de Oferta y Utilización 2010.

\section{Conclusiones y recomendaciones}

La información exógena de la DIAN es una fuente consistente y representativa de las transacciones de compray venta de la nación, que permite reproducir la Matriz Insumo Producto de consumo intermedio y los vectores de utilización y oferta. Si bien se puede considerar la existencia de un problema de subvaloración de las ventas y sobrevaloración de las compras, este inconveniente se resuelve metodológicamente al comparar coeficientes y participaciones, con lo cual se dejan de lado los valores absolutos. No es correcto hacer un contraste de los coeficientes en las divisiones de comercio, administración pública y defensa, las cuales no se encuentran cuantificadas por el DANE.

Del análisis de consistencia realizado a la información de oferta y utilización del DANE, se observa una débil correlación lineal: la información del DANE vector-utilización se correlaciona con la información del DANE vector-oferta en tan solo un $42 \%$, según el coeficiente de Pearson. En este sentido, para valorar la consistencia de la información de vector-utilización contra vector-oferta, vale la pena estudiar otro tipo de relaciones entre los vectores que no solo sean de carácter lineal, como lo evidencian los coeficientes de correlación no paramétrica, que para el caso de coeficiente Rho de Spearman alcanza el $75 \%$. La forma funcional de la relación del vector de ventas y el vector de utilización no es necesariamente lineal.

La comparación DIAN-DANE de los vectores de oferta y vectores de utilización permite ver las dinámicas de evasión. En particular, la información exógena de la DIAN muestra indicios de la evasión al encontrar diferencias entre los coeficientes, dando lugar a suponer que existe evasión del IVA en las divisiones de exportación de hidrocarburos y minerales, y el análisis de aquellas divisiones que, sin ser exportadoras, reportan diferencias, como en los servicios 
de correo y telecomunicaciones, así como los servicios de alojamiento, suministro de comidas y bebidas. La metodología también permite detectar evasión en uno de los sectores económicos tradicionalmente catalogado como evasor, que es el caso de trabajos de construcción y construcción de obras civiles.

A partir de los resultados y hallazgos de la investigación se recomiendan las siguientes líneas de acción para el control de la evasión del IVA en Colombia:

i) El procedimiento de análisis y aprovechamiento de la información exógena debe ir más allá de una fuente de contraste de los funcionarios de fiscalización de la DIAN, debe ser considerada igualmente relevante y valida a otras fuentes como las declaraciones tributarias. Se requiere que los contribuyentes comprendan que dar información inexacta en cualquiera de las fuentes de información de la administración tributaria es nocivo, grave e igualmente sujeto de sanción, por cuanto el Estatuto Tributario y Aduanero debería ser más explícito y severo al respecto.

ii) Establecer por parte de la DIAN mayor control y vigilancia de la tributación del IVA, a través de auditorías directas y recopilación de información de casos, en especial a aquellos sectores que ya han sido identificados como evasores. Se recomienda hacer un análisis de los modus operandi de los evasores en estos sectores, a través de estudios de casos que permitan a la Administración Tributaria DIAN llegar con acciones efectivas de control y sanción. Realizar constantemente las mismas rutinas de inspección hace que el control a la evasión sea predecible por los evasores.

iii) Establecer un programa piloto que permita realizar el seguimiento a la información entregada en medios magnéticos de la DIAN confrontada a la información reportada por el DANE. Esto no solo permite visibilizar nichos de evasión, sino fortalecer la vigilancia a través de la implementación de un tablero de control de calidad de la información que permita detectar de manera oportuna inconsistencias en los reportes de información.

\section{Referencias}

Ávila Mahecha, J. \& Cruz Lasso, A. (2007). Evasión del Impuesto al Valor Agregado (IVA) en Colombia: Estimación para el período 1998-2006. Bogotá: Oficina de Estudios Económicos de la DIAN, Colombia.

Cotte, A. (2014). Corruption, economic development and insecurity in Colombia. En Osman, I., Latef, A. \& Emrouznejad, A., Handbook of Research on Strategic Performance Management and Measurement Using Data Envelopment Analysis. Hershey, PA: IGI Global. 
Cotte, A. \& Lancheros, M. (2015). Emprendimiento, corrupción y crecimiento empresarial: un análisis para la industria manufacturera colombiana durante el período 2000-2011. Revista Métodos Cuantitativos para la Economía y la Empresa, 19, pp. 24-41.

Clavijo, S. (2007). Evolución de la tributación en Colombiay sus desafios (1990-2006), [en línea]. [Fecha de consulta: 24 de julio de 2014]. Disponible en: http://www.cepal.org/ilpes/noticias/paginas/2/27472/clavijo0107.pdf.

De Luis, J. (2009). Los instrumentos para la medición de la evasión tributaria. Series de Manuales CEPAL, 62. II.

Garzón, E. (1996). Acerca del concepto de corrupción. Córdoba: ITAM - Estudios Filosofia Historia Letras.

Imam, P. \& Jacobs, D. (2007). Effect of Corruption on Tax Revenues in the Middle East. Washington D.C.: Fondo Monetario Internacional.

Jorrat, M. (1996). Evaluación de la capacidad recaudatoria del sistema tributario y de la evasión tributaria, [en línea]. [Fecha de consulta: 3 de marzo de 2014]. Disponible en: http:// www.sii.cl/aprenda_sobre_impuestos/estudios/ciat96.htm.

Lora, E. (2008). Técnicas de medición económica, metodología y aplicaciones en Colombia (4a ed.). Bogotá: Alfaomega Colombiana S.A.

Macías, H., Agudelo, L. \& López, M. (2007). Evasión de impuestos y cumplimiento voluntario en Colombia. Medellín: Grupo de Investigaciones Contables y Gestión Pública.

Morales, M. (2009). Corrupción y democracia: América Latina en perspectiva comparada. Revista de Gestión Pública y Política. Volumen XVIII. Número 2. Santiago: CIDE.

Steiner y Soto (1998), "Evasión del impuesto a la renta en Colombia 1988-1995". Bogotá, Colombia.

Villlegas, H. B. (2002). Curso de finanzas, derecho financiero y tributario (8 $8^{\mathrm{a}}$ ed.). Buenos Aires: Editorial Astrea.

Yikona, S. (2011). Cómo la corrupción y la evasión de impuestos alteran al desarrollo, [en línea]. [Fecha de consulta: 6 de febrero de 2014]. Disponible en: http://blogs.worldbank. $\mathrm{org} /$ voices/es/c-mo-la-corrupci-n-y-la-evasi-n-de-impuestos-alteran-al-desarrollo. 


\section{Anexos}

\section{Anexo 1}

Tabla 7. De comparación de los vectores oferta

\begin{tabular}{|c|c|c|c|}
\hline División & Descripción división & DIAN $^{1}$ & DANE $^{2}$ \\
\hline 1 & Productos de café & 117 & 4724 \\
\hline 2 & Otros productos agrícolas & 5332 & 33379 \\
\hline 3 & Animales vivos, productos animales y productos de la caza & 4845 & 19758 \\
\hline 4 & $\begin{array}{l}\text { Productos de silvicultura, extracción de madera y actividades } \\
\text { conexas }\end{array}$ & 176 & 1708 \\
\hline 5 & Productos de la pesca, la acuicultura y servicios relacionados & 422 & 1585 \\
\hline 6 & Carbón mineral & 2187 & 11156 \\
\hline 7 & Petróleo crudo, gas natural y minerales de uranio y torio & 19837 & 39088 \\
\hline 8 & Minerales metálicos & 1083 & 5956 \\
\hline 9 & Minerales no metálicos & 534 & 3376 \\
\hline 10 & Carnes y pescados & 3168 & 20274 \\
\hline 11 & Aceites y grasas animales y vegetales & 2942 & 7914 \\
\hline 12 & Productos lácteos & 4254 & 8974 \\
\hline 13 & Productos de molinería, almidones y sus productos & 8667 & 21359 \\
\hline 14 & Productos de café y trilla & 915 & 6099 \\
\hline 15 & Azúcar y panela & 3726 & 5810 \\
\hline 16 & Cacao, chocolate y productos de confitería & 1562 & 3231 \\
\hline 17 & Productos alimenticios n.c.p & 3846 & 6933 \\
\hline 18 & Bebidas & 6658 & 19694 \\
\hline 19 & Productos de tabaco & 461 & 2533 \\
\hline 20 & $\begin{array}{l}\text { Fibras textiles naturales, hilazas e hilos; tejidos de fibras } \\
\text { textiles, incluso afelpados }\end{array}$ & 2486 & 4405 \\
\hline
\end{tabular}

1 La información insumo de este cálculo es aquella que no tiene errores de información. Se entiende por error aquel informante que reporte ventas superiores a 7,776 miles de millones de pesos, ventas que logró EPM en 2010, quien tuvo el top de venta en 2010 (http://rankings.americaeconomia.com/2011/500/las-que-mas-crecieron-en-ventas.php). En el mismo sentido, una venta presenta error en el reporte siempre que no se tenga información del comprador.

2 El vector DANE hace referencia a la producción de cada división. Por ello, el lector debe percatarse que esta no necesariamente es igual o inferior al Producto Interno Bruto-PIB. 


\begin{tabular}{|c|c|c|c|}
\hline División & Descripción división & DIAN & DANE \\
\hline 21 & Artículos textiles, excepto prendas de vestir & 633 & 4085 \\
\hline 22 & Tejidos de punto y ganchillo; prendas de vestir & 3811 & 19984 \\
\hline 23 & Gurtido y preparado de cueros, productos de cuero y calzado & 915 & 7331 \\
\hline 24 & Productos de madera, corcho, paja y materiales trenzables & 613 & 3435 \\
\hline 25 & Productos de papel, cartón y sus productos & 4053 & 10713 \\
\hline 26 & Edición, impresión y artículos análogos & 2914 & 8071 \\
\hline 27 & Productos de la refinación del petróleo; combustible nuclear & 691 & 36663 \\
\hline 28 & Sustancias y productos químicos & 14871 & 53176 \\
\hline 29 & Productos de caucho y de plástico & 5557 & 13937 \\
\hline 30 & Productos minerales no metálicos & 6698 & 14827 \\
\hline 31 & Productos metalúrgicos básicos (excepto maquinaria y equipo) & 7113 & 27496 \\
\hline 32 & Maquinaria y equipo & 2135 & 17915 \\
\hline 33 & Otra maquinaria y suministro eléctrico & 2236 & 23605 \\
\hline 34 & Equipo de transporte & 5820 & 25425 \\
\hline 35 & Muebles & 1056 & 5548 \\
\hline 36 & Otros bienes manufacturados n.c.p. & 1817 & 7599 \\
\hline 37 & Desperdicios y desechos & 333 & 2939 \\
\hline 38 & Energía eléctrica & 11848 & 24941 \\
\hline 39 & Gas domiciliario & 1380 & 4060 \\
\hline 40 & Agua & 490 & 3964 \\
\hline 43 & Comercio & 108706 & 0 \\
\hline 44 & $\begin{array}{l}\text { Servicios de reparación de automotores, de artículos } \\
\text { personales y domésticos }\end{array}$ & 866 & 13774 \\
\hline 45 & Servicios de alojamiento, suministro de comidas y bebidas & 2070 & 40865 \\
\hline 46 & Servicios de transporte terrestre & 16574 & 32970 \\
\hline 47 & Servicios de transporte por vía acuática & 300 & 1078 \\
\hline 48 & Servicios de transporte por vía aérea & 1750 & 6430 \\
\hline 49 & Servicios complementarios y auxiliares al transporte & 3763 & 7125 \\
\hline 50 & Servicios de correos y telecomunicaciones & 8050 & 26295 \\
\hline 51 & $\begin{array}{l}\text { Servicios de intermediación financiera, de seguros y servicios } \\
\text { conexos }\end{array}$ & 89675 & 45965 \\
\hline 52 & Servicios inmobiliarios y de alquiler de vivienda & 2116 & 53323 \\
\hline 53 & $\begin{array}{l}\text { Servicios a las empresas excepto servicios financieros e } \\
\text { inmobiliarios }\end{array}$ & 31940 & 64283 \\
\hline 54 & $\begin{array}{l}\text { Administración pública y defensa; dirección, administración y } \\
\text { control del sistema de seguridad social }\end{array}$ & 35434 & 52825 \\
\hline 55 & Servicios de enseñanza de mercado & 181 & 14144 \\
\hline 56 & Servicios de enseñanza de no mercado & 353 & 18589 \\
\hline 57 & Servicios sociales y de salud de mercado & 4442 & 30428 \\
\hline
\end{tabular}




\begin{tabular}{|c|l|c|c|}
\hline División & \multicolumn{1}{|c|}{ Descripción división } & DIAN & DANE \\
\hline 41 y 42 & $\begin{array}{l}\text { Trabajos de construcción, construcción de obras civiles y } \\
\text { servicios de arrendamiento de equipo con operario }\end{array}$ & 21949 & 81068 \\
\hline 59 y 60 & $\begin{array}{l}\text { Servicios de asociaciones y esparcimiento, culturales, } \\
\text { deportivos y otros servicios de no mercado }\end{array}$ & 9325 & 20638 \\
\hline & Total & 485699 & 1053470 \\
\hline
\end{tabular}

Fuente: vector DIAN cálculos propios basados en la información F1007 año 2010.

Vector DANE tomado de la página WEB DANE -Cuentas Nacionales-Anuales Matriz de Oferta 2010.

\section{Anexo 2}

Tabla 8. De comparación de los vectores utilización

\begin{tabular}{|c|l|c|c|}
\hline División & \multicolumn{1}{|c}{ Descripción división } & DIAN & DANE \\
\hline 1 & Productos de café & 340 & 4168 \\
\hline 2 & Otros productos agrícolas & 4489 & 13385 \\
\hline 3 & Animales vivos, productos animales y productos de la caza & 5204 & 15063 \\
\hline 4 & $\begin{array}{l}\text { Productos de silvicultura, extracción de madera y actividades } \\
\text { conexas }\end{array}$ & 93 & 1227 \\
\hline 5 & Productos de la pesca, la acuicultura y servicios relacionados & 486 & 762 \\
\hline 6 & Carbón mineral & 3436 & 657 \\
\hline 7 & Petróleo crudo, gas natural y minerales de uranio y torio & 24573 & 13365 \\
\hline 8 & Minerales metálicos & 1534 & 3905 \\
\hline 9 & Minerales no metálicos & 388 & 3070 \\
\hline 10 & Carnes y pescados & 2488 & 4875 \\
\hline 11 & Aceites y grasas animales y vegetales & 2208 & 4808 \\
\hline 12 & Productos lácteos & 2272 & 1378 \\
\hline 13 & Productos de molinería, almidones y sus productos & 5013 & 9393 \\
\hline 14 & Productos de café y trilla & 744 & 1148 \\
\hline 15 & Azúcar y panela & 1953 & 1884 \\
\hline 16 & Cacao, chocolate y productos de confitería & 2109 & 399 \\
\hline 17 & Productos alimenticios n.c.p & 3521 & 1860 \\
\hline 18 & Bebidas & 6614 & 5347 \\
\hline 19 & Productos de tabaco & 183 & 8 \\
\hline 21 & Fibras textiles naturales, hilazas e hilos; tejidos de fibras & 1283 & 3940 \\
\hline & textiles, incluso afelpados & 496 & 1201 \\
\hline
\end{tabular}

3 Ibídem.

4 El vector DANE hace referencia a la utilización de la producción de cada división. Por ello, el lector debe percatarse que esta debe ser similar al Producto Interno Bruto-PIB. 


\begin{tabular}{|c|c|c|c|}
\hline División & Descripción división & DIAN & DANE \\
\hline 22 & Tejidos de punto y ganchillo; prendas de vestir & 3773 & 2561 \\
\hline 23 & Curtido y preparado de cueros, productos de cuero y calzado & 928 & 1203 \\
\hline 24 & Productos de madera, corcho, paja y materiales trenzables & 474 & 3249 \\
\hline 25 & Productos de papel, cartón y sus productos & 3864 & 8137 \\
\hline 26 & Edición, impresión y artículos análogos & 1777 & 5084 \\
\hline 27 & Productos de la refinación del petróleo; combustible nuclear & 4712 & 20152 \\
\hline 28 & Sustancias y productos químicos & 8806 & 28360 \\
\hline 29 & Productos de caucho y de plástico & 3518 & 11578 \\
\hline 30 & Productos minerales no metálicos & 4112 & 13673 \\
\hline 31 & Productos metalúrgicos básicos (excepto maquinaria y equipo) & 3907 & 19271 \\
\hline 32 & Maquinaria y equipo & 1096 & 5401 \\
\hline 33 & Otra maquinaria y suministro eléctrico & 1096 & 7359 \\
\hline 34 & Equipo de transporte & 2320 & 6994 \\
\hline 35 & Muebles & 868 & 1216 \\
\hline 36 & Otros bienes manufacturados n.c.p. & 1127 & 1215 \\
\hline 37 & Desperdicios y desechos & 355 & 2236 \\
\hline 38 & Energía eléctrica & 13168 & 17083 \\
\hline 39 & Gas domiciliario & 2246 & 2000 \\
\hline 40 & Agua & 1516 & 1179 \\
\hline 43 & Comercio & 137026 & 0 \\
\hline 44 & $\begin{array}{l}\text { Servicios de reparación de automotores, de artículos } \\
\text { personales y domésticos }\end{array}$ & 1029 & 9111 \\
\hline 45 & Servicios de alojamiento, suministro de comidas y bebidas & 4091 & 6278 \\
\hline 46 & Servicios de transporte terrestre & 15705 & 13503 \\
\hline 47 & Servicios de transporte por vía acuática & 193 & 675 \\
\hline 48 & Servicios de transporte por vía aérea & 2790 & 3367 \\
\hline 49 & Servicios complementarios y auxiliares al transporte & 3743 & 5298 \\
\hline 50 & Servicios de correos y telecomunicaciones & 8735 & 8982 \\
\hline 51 & $\begin{array}{l}\text { Servicios de intermediación financiera, de seguros y servicios } \\
\text { conexos }\end{array}$ & 102129 & 30266 \\
\hline 52 & Servicios inmobiliarios y de alquiler de vivienda & 2928 & 12521 \\
\hline 53 & $\begin{array}{l}\text { Servicios a las empresas excepto servicios financieros e } \\
\text { inmobiliarios }\end{array}$ & 22014 & 59185 \\
\hline 54 & $\begin{array}{l}\text { Administración pública y defensa; dirección, administración y } \\
\text { control del sistema de seguridad social }\end{array}$ & 53287 & 0 \\
\hline 55 & Servicios de enseñanza de mercado & 177 & 573 \\
\hline 56 & Servicios de enseñanza de no mercado & 250 & 0 \\
\hline 57 & Servicios sociales y de salud de mercado & 4420 & 9068 \\
\hline 41 y 42 & $\begin{array}{l}\text { Trabajos de construcción, construcción de obras civiles y } \\
\text { servicios de arrendamiento de equipo con operario }\end{array}$ & 24612 & 7331 \\
\hline
\end{tabular}




\begin{tabular}{|c|c|c|c|}
\hline División & Descripción división & DIAN & DANE \\
\hline 59 y 60 & $\begin{array}{l}\text { Servicios de asociaciones y esparcimiento, culturales, } \\
\text { deportivos y otros servicios de no mercado }\end{array}$ & 5800 & 5772 \\
\hline
\end{tabular}

\section{Anexo 3}

\section{De homologación DIAN-DANE y divisiones de análisis}

La unidad de medición económica de la DIAN es el código de actividad económica, el cual corresponde a la suma actividades de productos, bienes y los servicios que tienen como característica común un grupo homogéneo de productos, bienes o servicios. El DANE, por su parte, considera como unidad de medición económica para la MIP la división económica, la cual corresponde a la suma actividades económicas que tienen como producción característica un grupo homogéneo de productos. Debido a la disparidad entre actividad económica y división económica se requiere de la utilización de una homologación; esta la elabora el $\mathrm{DANE}^{5}$ y a continuación se cita la utilizada como insumo base de este trabajo.

Tabla 9. Homologación CIIU V3.1 - Actividad económica DIAN 2010

\begin{tabular}{|c|c|c|c|c|c|c|c|}
\hline $\begin{array}{c}\text { Actividad } \\
\text { DIAN }\end{array}$ & $\begin{array}{c}\text { División } \\
\text { GIIU- } \\
\text { DANE }\end{array}$ & $\begin{array}{c}\text { Actividad } \\
\text { DIAN }\end{array}$ & $\begin{array}{c}\text { División } \\
\text { GIIU- } \\
\text { DANE }\end{array}$ & $\begin{array}{c}\text { Actividad } \\
\text { DIAN }\end{array}$ & $\begin{array}{c}\text { División } \\
\text { GIIU- } \\
\text { DANE }\end{array}$ & $\begin{array}{c}\text { Actividad } \\
\text { DIAN }\end{array}$ & $\begin{array}{c}\text { División } \\
\text { GIIU- } \\
\text { DANE }\end{array}$ \\
\hline 111 & 1 & 1432 & 9 & 1924 & 23 & 2519 & 29 \\
\hline 112 & 2 & 1490 & 9 & 1925 & 23 & 2521 & 29 \\
\hline 113 & 2 & 1511 & 10 & 1926 & 23 & 2529 & 29 \\
\hline 114 & 2 & 1512 & 10 & 1929 & 23 & 2610 & 30 \\
\hline 115 & 2 & 1521 & 17 & 1931 & 23 & 2691 & 30 \\
\hline 116 & 2 & 1522 & 11 & 1932 & 23 & 2692 & 30 \\
\hline 117 & 2 & 1530 & 12 & 1939 & 23 & 2693 & 30 \\
\hline 121 & 2 & 1541 & 13 & 2010 & 24 & 2694 & 30 \\
\hline 122 & 2 & 1542 & 13 & 2020 & 24 & 2695 & 30 \\
\hline 123 & 3 & 1543 & 13 & 2030 & 24 & 2696 & 30 \\
\hline 125 & 3 & 1561 & 14 & 2040 & 24 & 2699 & 30 \\
\hline
\end{tabular}

5 Ver: http://www.dane.gov.co/files/nomenclaturas/tablasCorrelativas 
ISSN: 0124-3551 / Año 17, No 26 / enero-junio / pp. 37-74

\begin{tabular}{|c|c|c|c|c|c|c|c|}
\hline $\begin{array}{l}\text { Actividad } \\
\text { DIAN }\end{array}$ & $\begin{array}{c}\text { División } \\
\text { GIIU- } \\
\text { DANE }\end{array}$ & $\begin{array}{l}\text { Actividad } \\
\text { DIAN }\end{array}$ & $\begin{array}{c}\text { División } \\
\text { CIIU- } \\
\text { DANE }\end{array}$ & $\begin{array}{l}\text { Actividad } \\
\text { DIAN }\end{array}$ & $\begin{array}{c}\text { División } \\
\text { CIIU- } \\
\text { DANE }\end{array}$ & $\begin{array}{l}\text { Actividad } \\
\text { DIAN }\end{array}$ & $\begin{array}{c}\text { División } \\
\text { CIIU- } \\
\text { DANE }\end{array}$ \\
\hline 129 & 3 & 1571 & 15 & 2109 & 25 & 2731 & 31 \\
\hline 130 & 2 & 1572 & 15 & 2211 & 26 & 2732 & 31 \\
\hline 140 & 2 & 1581 & 16 & 2212 & 26 & 2811 & 31 \\
\hline 201 & 4 & 1582 & 13 & 2213 & 26 & 2812 & 31 \\
\hline 202 & 4 & 1583 & 13 & 2219 & 26 & 2813 & 31 \\
\hline 501 & 5 & 1589 & 17 & 2220 & 26 & 2891 & 31 \\
\hline 502 & 5 & 1591 & 18 & 2230 & 26 & 2892 & 31 \\
\hline 1010 & 6 & 1592 & 18 & 2240 & 26 & 2893 & 31 \\
\hline 1020 & 6 & 1593 & 18 & 2310 & 27 & 2899 & 31 \\
\hline 1030 & 6 & 1594 & 18 & 2321 & 27 & 2911 & 32 \\
\hline 1110 & 7 & 1600 & 19 & 2322 & 27 & 2912 & 32 \\
\hline 1120 & 7 & 1710 & 20 & 2330 & 27 & 2913 & 32 \\
\hline 1200 & 7 & 1720 & 20 & 2411 & 28 & 2914 & 32 \\
\hline 1310 & 8 & 1730 & 20 & 2412 & 28 & 2915 & 32 \\
\hline 1320 & 8 & 1741 & 21 & 2413 & 28 & 2919 & 32 \\
\hline 1331 & 8 & 1742 & 21 & 2414 & 28 & 2921 & 32 \\
\hline 1339 & 8 & 1743 & 21 & 2421 & 28 & 2922 & 32 \\
\hline 1411 & 9 & 1749 & 21 & 2422 & 28 & 2923 & 32 \\
\hline 1412 & 9 & 1750 & 22 & 2423 & 28 & 2924 & 32 \\
\hline 1413 & 9 & 1810 & 22 & 2424 & 28 & 2925 & 32 \\
\hline 1414 & 9 & 1820 & 22 & 2429 & 28 & 2926 & 32 \\
\hline 1415 & 9 & 1910 & 23 & 2430 & 28 & 2927 & 32 \\
\hline 1421 & 9 & 1921 & 23 & 2511 & 29 & 2929 & 32 \\
\hline 1422 & 9 & 1922 & 23 & 2512 & 29 & 2930 & 32 \\
\hline 1431 & 9 & 1923 & 23 & 2513 & 29 & 3000 & 33 \\
\hline 3110 & 33 & 4100 & 40 & 5139 & 43 & 5249 & 43 \\
\hline 3120 & 33 & 4511 & 41 y 42 & 5141 & 43 & 5251 & 43 \\
\hline 3130 & 33 & 4512 & 41 y 42 & 5142 & 43 & 5252 & 43 \\
\hline 3140 & 33 & 4521 & 41 y 42 & 5151 & 43 & 5261 & 43 \\
\hline 3150 & 33 & 4522 & 41 y 42 & 5152 & 43 & 5262 & 43 \\
\hline 3190 & 33 & 4530 & 41 y 42 & 5153 & 43 & 5269 & 43 \\
\hline 3210 & 33 & 4541 & 41 y 42 & 5154 & 43 & 5271 & 44 \\
\hline 3220 & 33 & 4542 & 41 y 42 & 5155 & 43 & 5272 & 44 \\
\hline 3230 & 33 & 4543 & 41 y 42 & 5159 & 43 & 5511 & 45 \\
\hline 3311 & 33 & 4549 & 41 y 42 & 5161 & 43 & 5512 & 45 \\
\hline 3312 & 33 & 4551 & 41 y 42 & 5162 & 43 & 5513 & 45 \\
\hline 3313 & 33 & 4552 & 41 y 42 & 5163 & 43 & 5519 & 45 \\
\hline
\end{tabular}




\begin{tabular}{|c|c|c|c|c|c|c|c|}
\hline $\begin{array}{l}\text { Actividad } \\
\text { DIAN }\end{array}$ & $\begin{array}{c}\text { División } \\
\text { CIIU- } \\
\text { DANE }\end{array}$ & $\begin{array}{l}\text { Actividad } \\
\text { DIAN }\end{array}$ & $\begin{array}{c}\text { División } \\
\text { CIIU- } \\
\text { DANE }\end{array}$ & $\begin{array}{l}\text { Actividad } \\
\text { DIAN }\end{array}$ & $\begin{array}{c}\text { División } \\
\text { CIIU- } \\
\text { DANE }\end{array}$ & $\begin{array}{l}\text { Actividad } \\
\text { DIAN }\end{array}$ & $\begin{array}{c}\text { División } \\
\text { CIIU- } \\
\text { DANE }\end{array}$ \\
\hline 3320 & 33 & 4559 & 41 y 42 & 5164 & 43 & 5521 & 45 \\
\hline 3330 & 33 & 4560 & 41 y 42 & 5165 & 43 & 5522 & 45 \\
\hline 3410 & 34 & 5011 & 43 & 5169 & 43 & 5523 & 45 \\
\hline 3420 & 34 & 5012 & 43 & 5170 & 44 & 5524 & 45 \\
\hline 3430 & 34 & 5020 & 44 & 5190 & 43 & 5529 & 45 \\
\hline 3511 & 34 & 5030 & 43 & 5211 & 43 & 5530 & 45 \\
\hline 3512 & 34 & 5040 & 43 & 5219 & 43 & 6010 & 46 \\
\hline 3520 & 34 & 5051 & 43 & 5221 & 43 & 6021 & 46 \\
\hline 3530 & 34 & 5052 & 43 & 5222 & 43 & 6022 & 46 \\
\hline 3591 & 34 & 5111 & 43 & 5223 & 43 & 6023 & 46 \\
\hline 3592 & 34 & 5112 & 43 & 5224 & 43 & 6031 & 46 \\
\hline 3599 & 34 & 5113 & 43 & 5225 & 43 & 6032 & 46 \\
\hline 3611 & 35 & 5119 & 43 & 5229 & 43 & 6039 & 46 \\
\hline 3612 & 35 & 5121 & 43 & 5231 & 43 & 6041 & 46 \\
\hline 3613 & 35 & 5122 & 43 & 5232 & 43 & 6042 & 46 \\
\hline 3614 & 35 & 5123 & 43 & 5233 & 43 & 6043 & 46 \\
\hline 3619 & 35 & 5124 & 43 & 5234 & 43 & 6044 & 46 \\
\hline 3691 & 36 & 5125 & 43 & 5235 & 43 & 6050 & 46 \\
\hline 3692 & 36 & 5126 & 43 & 5236 & 43 & 6111 & 47 \\
\hline 3693 & 36 & 5127 & 43 & 5237 & 43 & 6112 & 47 \\
\hline 3694 & 36 & 5131 & 43 & 5239 & 43 & 6120 & 47 \\
\hline 3699 & 36 & 5132 & 43 & 5241 & 43 & 6211 & 48 \\
\hline 3710 & 37 & 5133 & 43 & 5242 & 43 & 6212 & 48 \\
\hline 3720 & 37 & 5134 & 43 & 5243 & 43 & 6213 & 48 \\
\hline 4010 & 38 & 5135 & 43 & 5244 & 43 & 6214 & 48 \\
\hline 4020 & 39 & 5136 & 43 & 5245 & 43 & 6220 & 48 \\
\hline 4030 & 39 & 5137 & 43 & 5246 & 43 & 6310 & 49 \\
\hline 6320 & 49 & 6603 & 51 & 7320 & 53 & 9191 & 57 \\
\hline 6331 & 49 & 6604 & 51 & 7411 & 53 & 9192 & 57 \\
\hline 6332 & 49 & 6711 & 51 & 7412 & 53 & 9199 & 57 \\
\hline 6333 & 49 & 6712 & 51 & 7413 & 53 & 9211 & 59 y 60 \\
\hline 6339 & 49 & 6713 & 51 & 7414 & 53 & 9212 & 59 y 60 \\
\hline 6340 & 49 & 6714 & 51 & 7421 & 53 & 9213 & 59 y 60 \\
\hline 6390 & 49 & 6715 & 51 & 7422 & 53 & 9214 & 59 y 60 \\
\hline 6411 & 50 & 6716 & 51 & 7430 & 53 & 9219 & 59 y 60 \\
\hline 6412 & 50 & 6717 & 51 & 7491 & 53 & 9220 & 59 y 60 \\
\hline 6421 & 50 & 6719 & 51 & 7492 & 53 & 9231 & 59 y 60 \\
\hline
\end{tabular}


ISSN: 0124-3551 / Año 17, No 26 / enero-junio / pp. 37-74

\begin{tabular}{|c|c|c|c|c|c|c|c|}
\hline 6422 & 50 & 6721 & 51 & 7493 & 53 & 9232 & 59 y 60 \\
\hline 6423 & 50 & 6722 & 51 & 7494 & 53 & 9233 & 59 y 60 \\
\hline 6424 & 50 & 7010 & 52 & 7495 & 53 & 9241 & 59 y 60 \\
\hline 6429 & 50 & 7020 & 52 & 7499 & 53 & 9242 & 59 y 60 \\
\hline 6511 & 51 & 7111 & 53 & 7511 & 54 & 9249 & 59 y 60 \\
\hline 6512 & 51 & 7112 & 53 & 7512 & 54 & 9301 & 59 y 60 \\
\hline 6513 & 51 & 7113 & 53 & 7513 & 54 & 9302 & 59 y 60 \\
\hline 6514 & 51 & 7121 & 53 & 7514 & 54 & 9303 & 59 y 60 \\
\hline 6515 & 51 & 7122 & 53 & 7515 & 54 & 9309 & 59 y 60 \\
\hline 6519 & 51 & 7123 & 53 & 7519 & 54 & 9500 & 61 \\
\hline 6591 & 51 & 7129 & 53 & 7521 & 54 & & \\
\hline 6592 & 51 & 7130 & 53 & 7522 & 54 & & \\
\hline 6593 & 51 & 7210 & 53 & 7523 & 54 & & \\
\hline 6594 & 51 & 7220 & 53 & 7524 & 54 & & \\
\hline 6595 & 51 & 7230 & 53 & 7530 & 54 & & \\
\hline 6596 & 51 & 7240 & 53 & 8011 & 55 & & \\
\hline 6599 & 51 & 7250 & 53 & 8090 & 56 & & \\
\hline 6601 & 51 & 7290 & 53 & 9111 & 59 & & \\
\hline 6602 & 51 & 7310 & 53 & 9120 & 57 & & \\
\hline
\end{tabular}




\section{Anexo 4}

\section{Modelamiento y validación de supuestos}

Para comparar si dos formas de medir un fenómeno o evento se aproximan o son equivalentes existen métodos que permiten analizar las diferencias. Para este documento en particular se utiliza un modelo de calibración basado en un modelo de regresión lineal simple. Se espera que si las estimaciones de los vectores de oferta y la utilización construidas desde la información de la DIAN son aproximadas a las del DANE los modelos de regresión lineal simple serán altamente significativos y darán cuenta de la forma de aproximar y equiparar las dos fuentes de información.

\section{Modelamiento combinación optima $\operatorname{DIAN}(S)-D A N E(R)$}

Gráfico 4. Dispersión de los coeficientes de Utilización DIAN-Oferta DANE

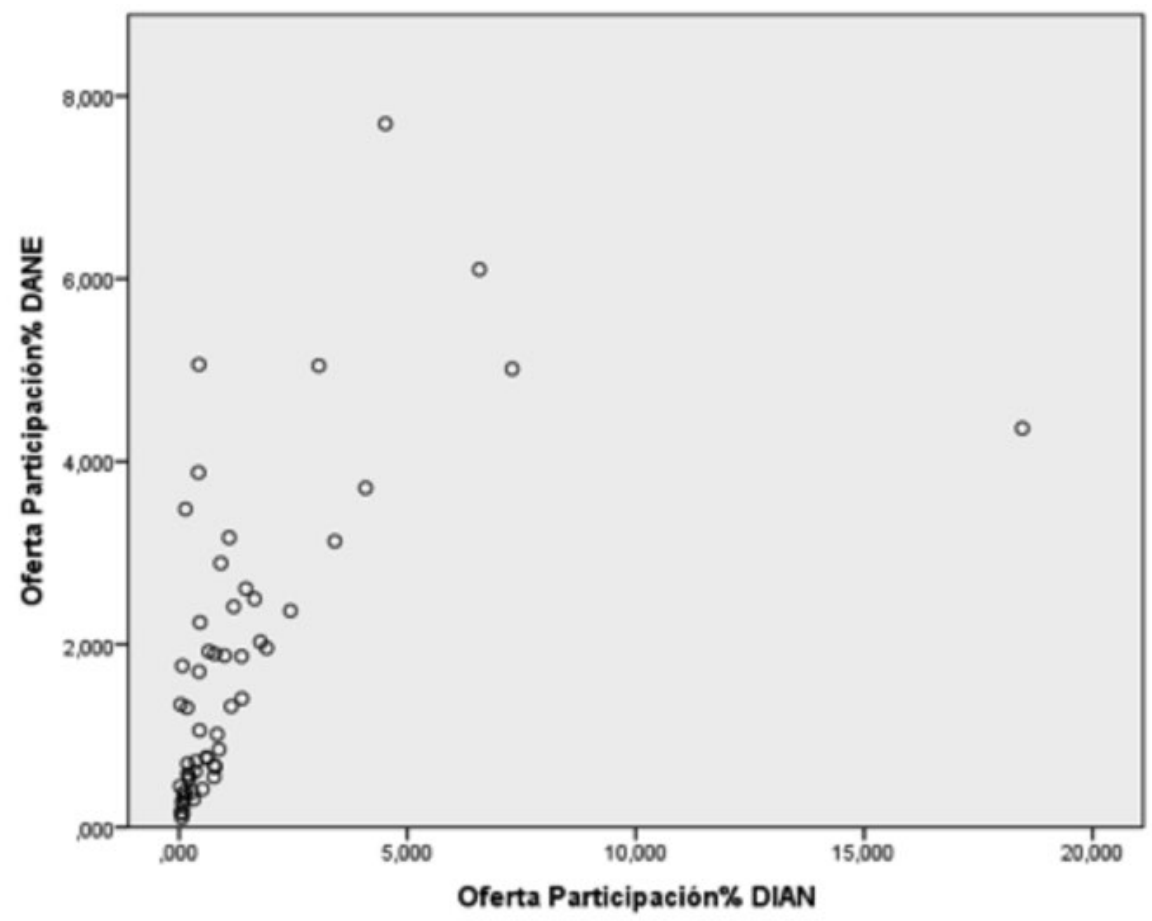

Fuente: vector DIAN cálculos propios basados en la información F1007 año 2010.

Vector DANE tomado de la página WEB DANE - Cuentas Nacionales-Anuales Matriz de Oferta 2010. 
Gráfico 5. Modelos de ajuste Utilización DIAN-Oferta DANE

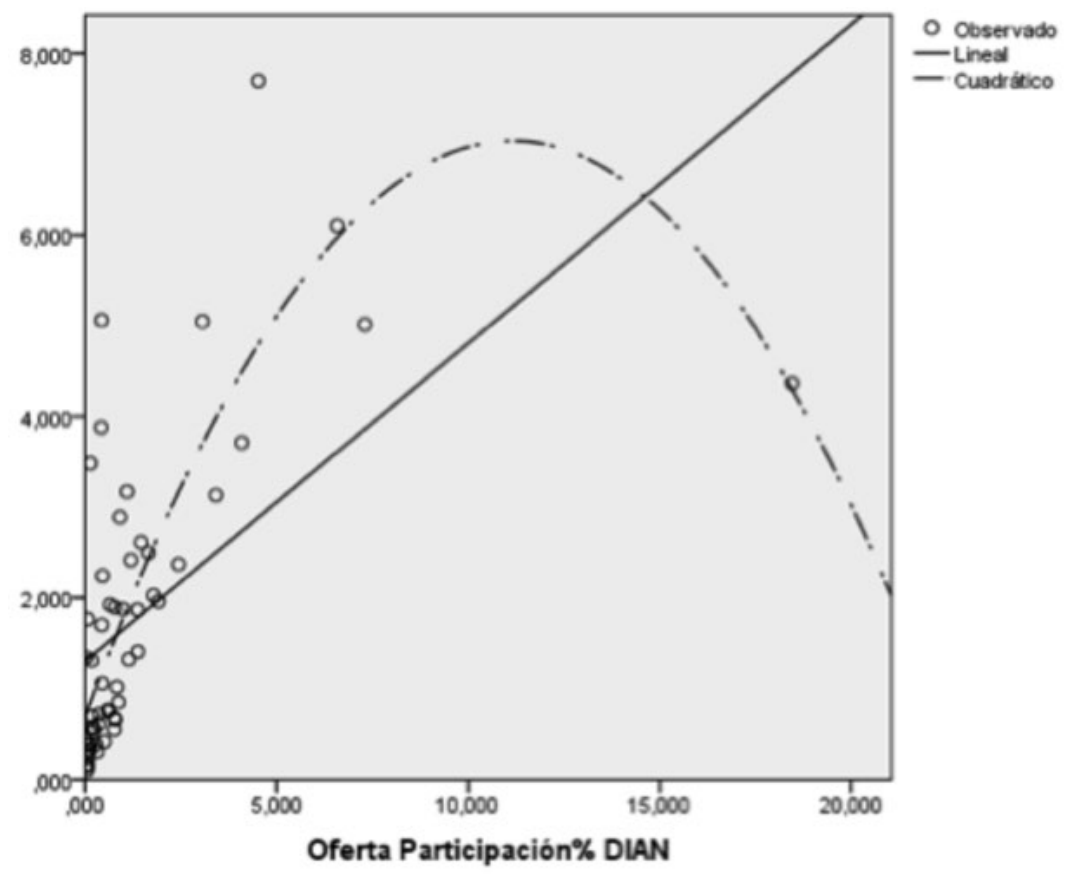

Fuente: vector DIAN cálculos propios basados en la información F1007 año 2010.

Vector DANE tomado de la página WEB DANE - Cuentas Nacionales-Anuales Matriz de Oferta 2010.

Tabla 10. Resultados del modelo de regresión cuadrático Utilización DIAN-Oferta DANE

\begin{tabular}{|c|c|c|c|}
\hline \multicolumn{4}{|c|}{ Resumen del modelo } \\
\hline $\mathbf{R}$ & $\mathbf{R}$ cuadrado & $\begin{array}{l}R \text { cuadrado } \\
\text { ajustado }\end{array}$ & $\begin{array}{c}\text { Error estándar de la } \\
\text { estimación }\end{array}$ \\
\hline, 761 &, 579 &, 564 & 1,114 \\
\hline
\end{tabular}

La variable independiente es Utilización DIAN.

\begin{tabular}{|c|c|c|c|c|c|}
\hline \multicolumn{6}{|c|}{ ANOVA } \\
\hline & $\begin{array}{l}\text { Suma de } \\
\text { cuadrados }\end{array}$ & gl & $\begin{array}{l}\text { Media cua- } \\
\text { drática }\end{array}$ & $\mathbf{F}$ & Sig. \\
\hline Regresión & 92,243 & 2 & 46,121 & 37,166 &, 000 \\
\hline Residuo & 67,012 & 54 & 1,241 & & \\
\hline Total & 159,254 & 56 & & & \\
\hline
\end{tabular}

La variable independiente es Utilización DIAN. 


\section{Coeficientes}

\begin{tabular}{|c|c|c|c|c|c|}
\hline & \multicolumn{2}{|c|}{$\begin{array}{l}\text { Coeficientes no } \\
\text { estandarizados }\end{array}$} & \multirow{2}{*}{$\begin{array}{c}\text { Coeficientes } \\
\text { estandarizados } \\
\text { Beta }\end{array}$} & \multirow[b]{2}{*}{$\mathbf{t}$} & \multirow[b]{2}{*}{ Sig. } \\
\hline & B & $\begin{array}{l}\text { Error } \\
\text { estándar }\end{array}$ & & & \\
\hline Utilización DIAN & 1,021 &, 119 & 2,706 & 8,608 &, 000 \\
\hline Utilización DIAN ** 2 &,- 041 &, 005 & $-2,555$ & $-8,128$ & ,000 \\
\hline (Constante) & ,888 &, 180 & & 4,924 &, 000 \\
\hline
\end{tabular}

Gráfico 6. Histograma de los residuos

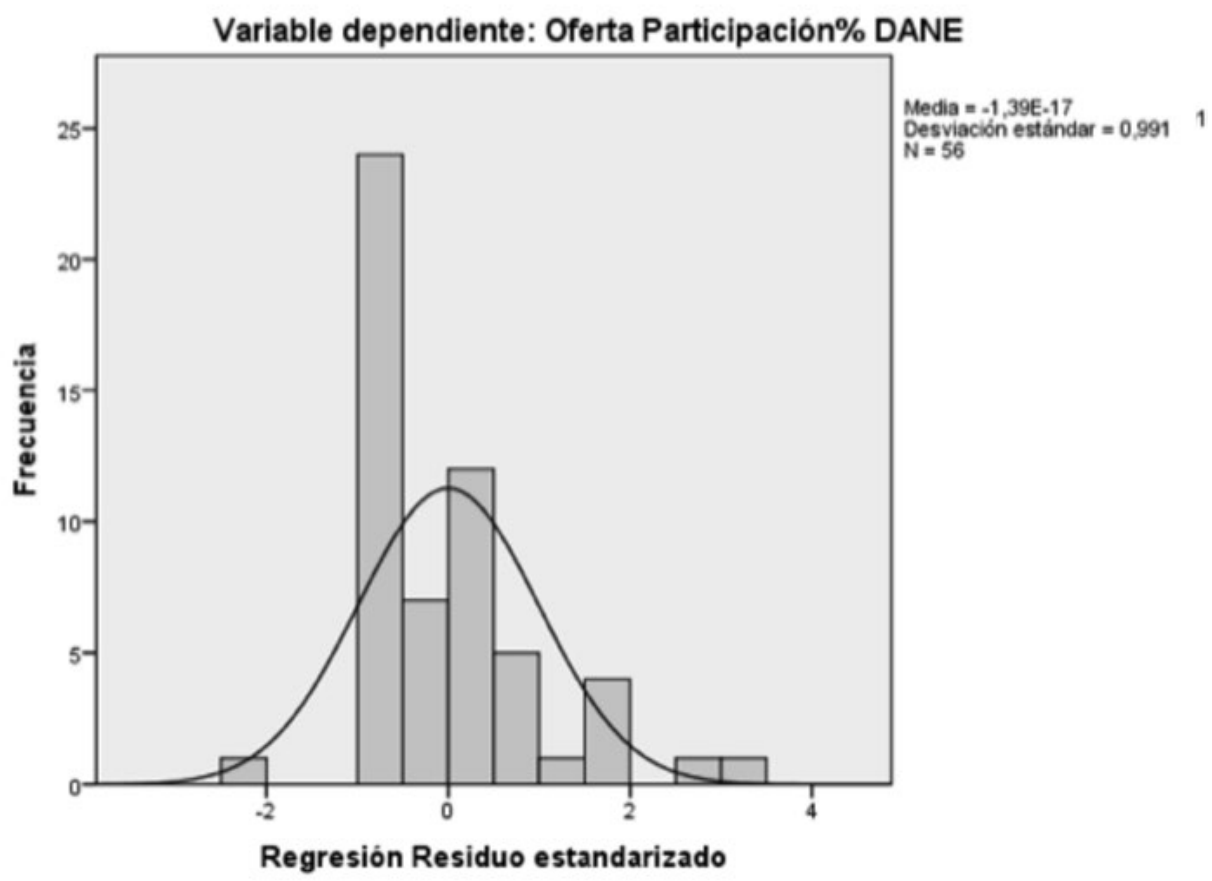

Fuente: vector DIAN cálculos propios basados en la información F1007 año 2010.

Vector DANE tomado de la página WEB DANE - Guentas Nacionales-Anuales Matriz de Oferta 2010. 
ISSN: 0124-3551 / Año 17, No 26 / enero-junio / pp. 37-74

\section{Modelamiento de los vectores de oferta}

Gráfico 7. Dispersión de los coeficientes de Oferta DIAN-Oferta DANE

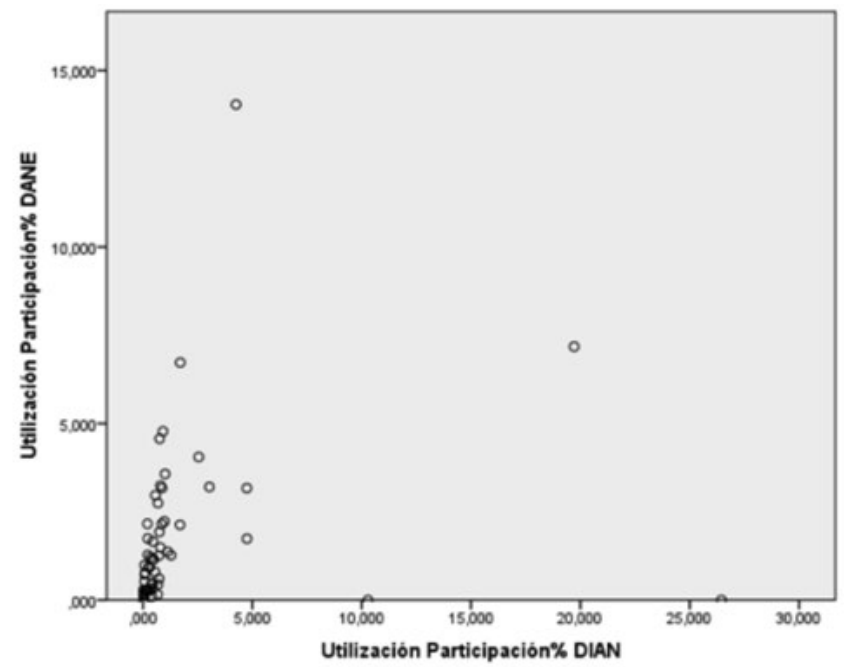

Fuente: vector DIAN cálculos propios basados en la información F1007 año 2010. Vector DANE tomado de la página WEB DANE - Cuentas Nacionales-Anuales Matriz de Oferta 2010.

Gráfico 8. Modelos de ajuste Oferta DIAN-Oferta DANE

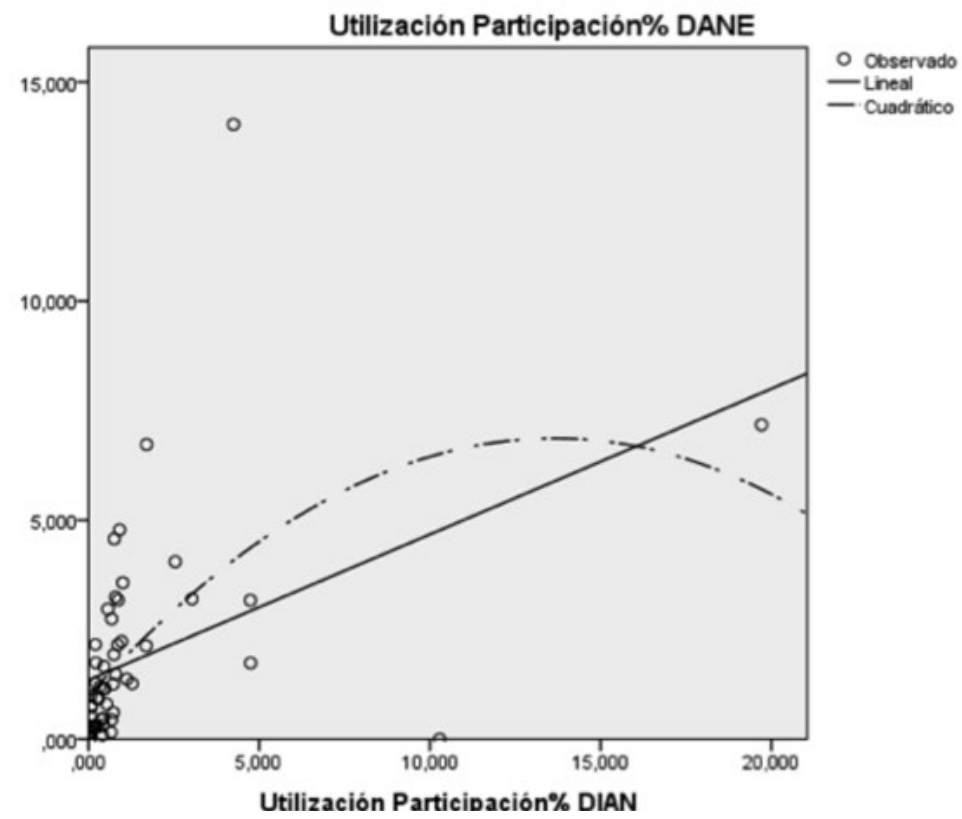

Fuente: vector DIAN cálculos propios basados en la información F1007 año 2010.

Vector DANE tomado de la página WEB DANE - Cuentas Nacionales-Anuales Matriz de Oferta 2010. 
Tabla 11. Resultados del modelo de regresión simple Oferta DIAN - Oferta DANE

\begin{tabular}{|c|c|c|c|c|c|}
\hline Modelo & R & R cuadrado & $\begin{array}{c}\text { R cuadrado } \\
\text { ajustado }\end{array}$ & $\begin{array}{c}\text { Error } \\
\text { estándar de la } \\
\text { estimación }\end{array}$ & $\begin{array}{c}\text { Durbin- } \\
\text { Watson }\end{array}$ \\
\hline 1 &, $577 \mathrm{a}$ &, 333 &, 320 & 1,388841 &, 698 \\
\hline
\end{tabular}

a. Variable dependiente: Oferta Participación\% DANE

\begin{tabular}{|c|c|c|c|c|c|}
\hline \multicolumn{6}{|c|}{ ANOVA } \\
\hline & $\begin{array}{l}\text { Suma de } \\
\text { cuadrados }\end{array}$ & gl & $\begin{array}{c}\text { Media } \\
\text { cuadrática }\end{array}$ & $\mathbf{F}$ & Sig. \\
\hline Regresión & 51,962 & 1 & 51,962 & 26,939 & ,000 \\
\hline Residuo & 104,159 & 54 & 1,929 & & \\
\hline Total & 156,122 & 55 & & & \\
\hline
\end{tabular}

La variable independiente es Oferta Participación\% DIAN.

\section{ESTADÍSTIGAS DE RESIDUOS ${ }^{a}$}

\begin{tabular}{|c|c|c|c|c|c|}
\hline & Mínimo & Máximo & Media & $\begin{array}{c}\text { Desviación } \\
\text { estándar }\end{array}$ & $\mathbf{N}$ \\
\hline Valor pronosticado & 1,30793 & 7,77654 & 1,78571 & ,971991 & 56 \\
\hline Residuo & $-3,413338$ & 4,810518 &, 000000 & 1,376157 & 56 \\
\hline Valor pronosticado estándar &,- 492 & 6,163 &, 000 & 1,000 & 56 \\
\hline Residuo estándar & $-2,458$ & 3,464 &, 000 &, 991 & 56 \\
\hline
\end{tabular}

a. Variable dependiente: Oferta Participación \% DANE

Gráfico 9. Histograma de los residuos

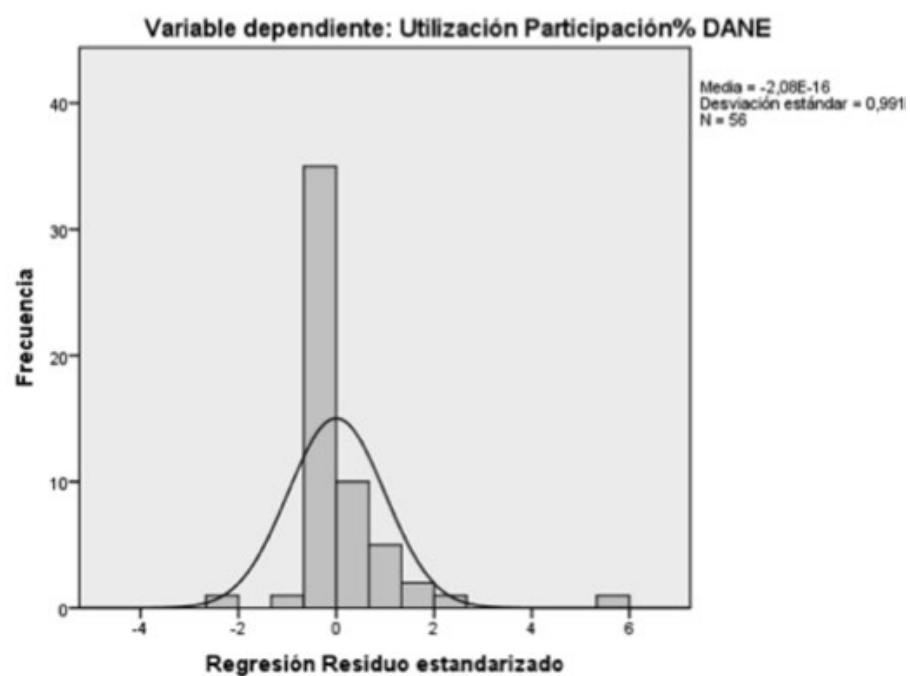

Fuente: vector DIAN cálculos propios información F1007 año 2010.

Vector DANE tomado de la página WEB DANE - Cuentas Nacionales-Anuales Matriz de Utilización 2010. 
ISSN: 0124-3551 / Año 17, No 26 / enero-junio / pp. 37-74

\section{Modelamiento de los vectores de Utilización}

Gráfico 10. Dispersión de los coeficientes de Utilización DIAN - Utilización DANE

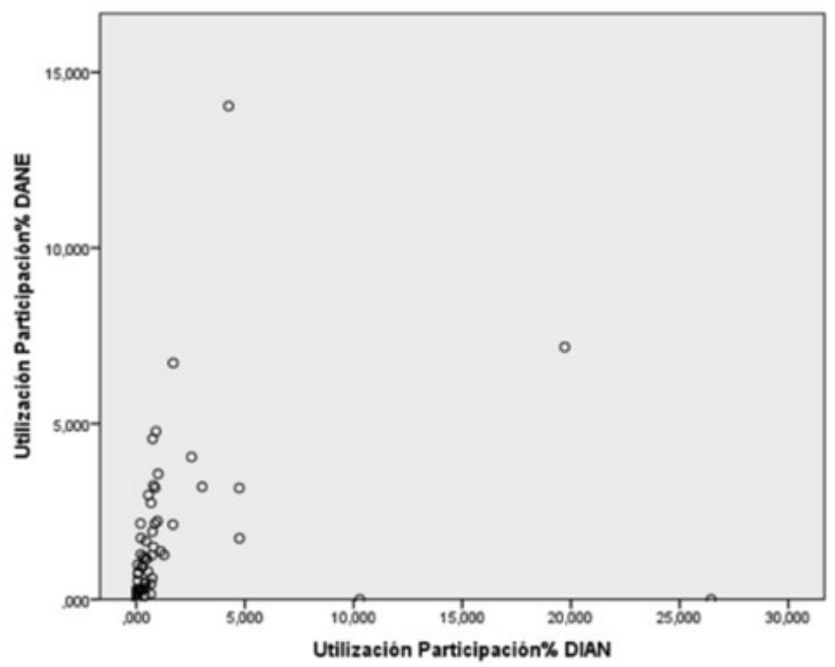

Fuente: vector DIAN cálculos propios basados en la información F1007 año 2010.

Vector DANE tomado de la página WEB DANE - Cuentas Nacionales-Anuales Matriz de Utilización 2010.

Gráfico 11. Modelos de ajuste Utilización DIAN - Utilización DANE

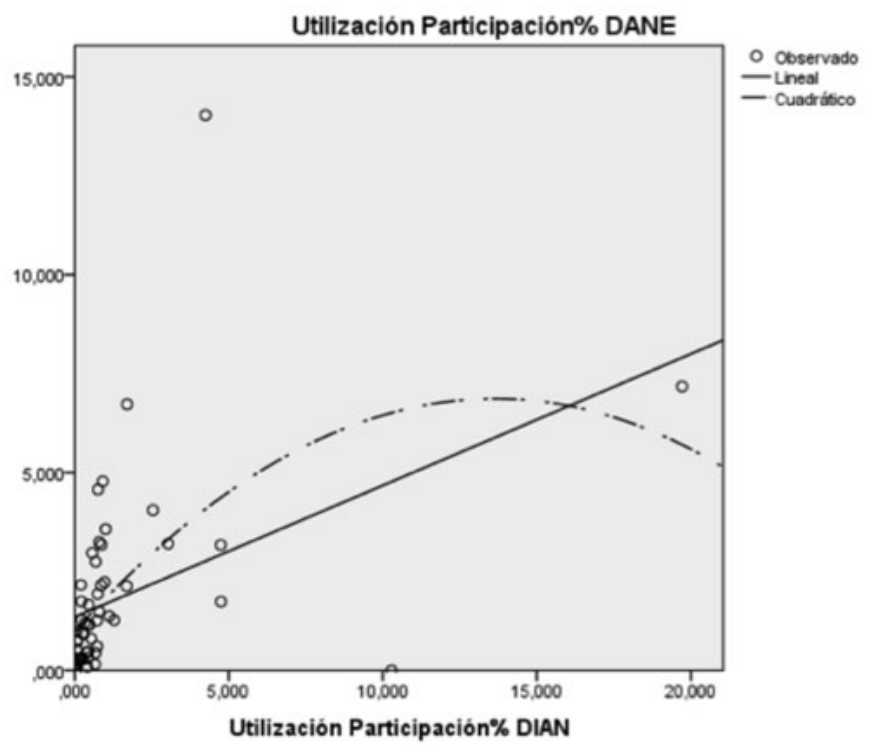

Fuente: Vector DIAN cálculos propios basados en la información F1007 año 2010.

Vector DANE tomado de la página WEB DANE - Cuentas Nacionales-Anuales Matriz de Oferta 2010. 
Tabla 12. Resultados del modelo de regresión simple Utilización DIAN-Utilización DANE

\begin{tabular}{|c|c|c|c|c|c|}
\hline Modelo & R & R cuadrado & $\begin{array}{c}\text { R cuadrado } \\
\text { ajustado }\end{array}$ & $\begin{array}{c}\text { Error } \\
\text { estándar de la } \\
\text { estimación }\end{array}$ & $\begin{array}{c}\text { Durbin- } \\
\text { Watson }\end{array}$ \\
\hline 1 &, $577 \mathrm{a}$ &, 333 &, 320 & 1,388841 &, 698 \\
\hline
\end{tabular}

a. Variable dependiente: Oferta Participación\% DANE

\begin{tabular}{|c|c|c|c|c|c|}
\hline \multicolumn{6}{|c|}{ ANOVA $^{\mathbf{a}}$} \\
\hline & $\begin{array}{c}\text { Suma de } \\
\text { cuadrados }\end{array}$ & gl & $\begin{array}{c}\text { Media } \\
\text { cuadrática }\end{array}$ & $\mathbf{F}$ & Sig. \\
\hline Regresión & 54,919 & 1 & 54,919 & 12,297 &, $001^{\mathrm{b}}$ \\
\hline Residuo & 241,158 & 54 & 4,466 & & \\
\hline Total & 296,077 & 55 & & & \\
\hline \multicolumn{6}{|c|}{ a. Variable dependiente: Utilización Participación\% DANE } \\
\hline \multicolumn{6}{|c|}{ b. Predictores: (Constante), Utilización Participación\% DIAN } \\
\hline
\end{tabular}

\begin{tabular}{|c|c|c|c|c|c|}
\hline \multicolumn{6}{|c|}{ ESTADÍSTICAS DE RESIDUOS ${ }^{a}$} \\
\hline & Mínimo & Máximo & Media & $\begin{array}{c}\text { Desviación } \\
\text { estándar }\end{array}$ & $\mathbf{N}$ \\
\hline Valor pronosticado & 1,35507 & 7,90322 & 1,78571 & ,999261 & 56 \\
\hline Residuo & $-4,76$ & 11,272210 & ,000000 & 2,093965 & 56 \\
\hline Valor pronosticado estándar &,- 431 & 6,122 &, 000 & 1,000 & 56 \\
\hline Residuo estándar & $-2,257$ & 5,334 &, 000 &, 991 & 56 \\
\hline
\end{tabular}

Gráfico 12. Histograma de los residuos

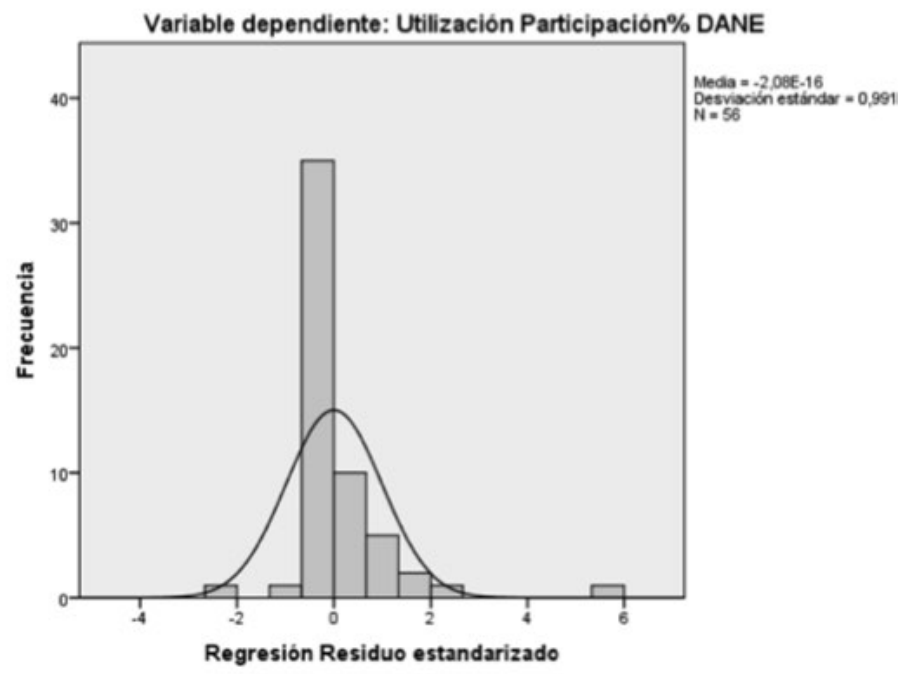




\section{Anexo 5: Comparación oferta y utilización}

\section{Comparación de los vectores de oferta}

Gráfico 13. Comparación participación de la Oferta DIAN-DANE

\section{PARTICIPACIÓN DE LA OFERTA}

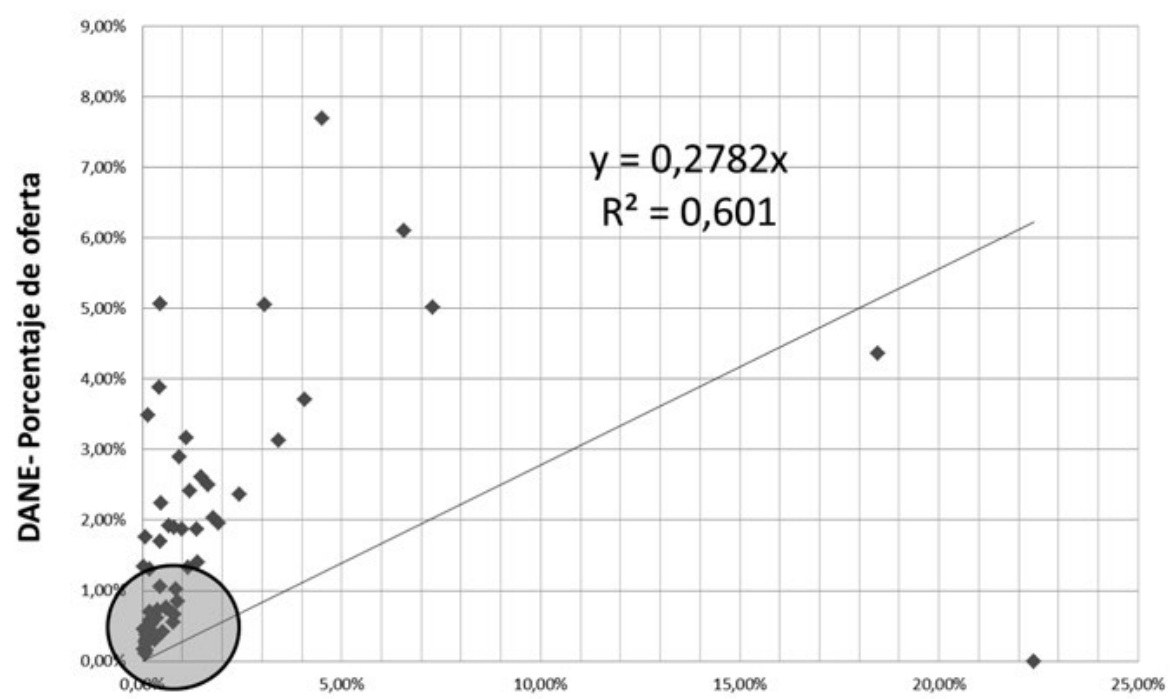

DIAN- Porcentaje de oferta

Fuente: vector DIAN cálculos propios basados en la información F1007 año 2010. Vector DANE tomado de la página WEB DANE - Cuentas Nacionales-Anuales Matriz de Oferta 2010

En el gráfico 13 se identifica que los valores de oferta del DANE están por encima de los valores calculados con la información de la DIAN. Estas diferencias permiten evidenciar que en el vector de oferta DANE la división de comercio - No. 43 no presenta valor de producción (ver tabla 14), mostrando una diferencia de 108.706 miles de millones de pesos con respecto al vector de oferta de la DIAN. Así mismo, en aquellas divisiones cuya descripción es servicios, encontramos que los valores de oferta DIAN son mayores a los valores de oferta DANE, debido a que la producción se define como un conjunto de productos, dejando los servicios fuera de las cuentas. Por último, la oferta total calculada por el DANE supera a la oferta calculada por la DIAN, lo que muestra que no todo lo que es resultado del proceso productivo del país resulta en una transacción de compra -venta interna, explicado por los resultados de las divisiones relacionadas en minería e hidrocarburos (No. 6, 7, 8 y 9).

De acuerdo con los resultados, se encuentra que DIAN y DANE no tienen valores absolutos cercanos (ver anexo 1). También se hace la comparación de los valores relativos 
de la participación de cada división (ver gráfico 13), el cual contiene en el eje X la participación de las divisiones en la oferta total con los cálculos DIAN, y en el eje Y la participación de las divisiones en la oferta total con los datos del DANE. Se espera que si estas dos metodologías miden de manera equivalente la participación de la división j en el total de la oferta, el modelo de regresión lineal simple que pasa por el origen sea el de mejor ajuste, al ser coincidentes las parejas de los ejes. Bajo esta premisa podemos decir que aquellos puntos que están más cercanos a la diagonal del gráfico 13 corresponden a las divisiones cuya participación en la oferta es similar (ver tabla 13), mientras las mayores discrepancias son aquellos puntos alejados de la diagonal, que para nuestro caso estarían indicando los nichos de evasión en IVA.

Tabla 13. Divisiones con participación similar de oferta DIAN-DANE

\begin{tabular}{|c|c|l|c|c|}
\hline Top & División & \multicolumn{1}{|c|}{ Descripción división } & $\begin{array}{c}\text { DANE } \\
\text { Participación oferta }\end{array}$ & $\begin{array}{c}\text { DIAN } \\
\text { Participación oferta }\end{array}$ \\
\hline 1 & 16 & $\begin{array}{l}\text { Cacao, chocolate y } \\
\text { productos de confitería }\end{array}$ & $0,3 \%$ & $0,3 \%$ \\
\hline 2 & 12 & $\begin{array}{l}\text { Productos lácteos } \\
\text { Productos minerales no }\end{array}$ & $0,9 \%$ & $0,9 \%$ \\
\hline 4 & 30 & $\begin{array}{l}\text { metálicos } \\
\text { Pervicios de asociaciones y }\end{array}$ & $1,4 \%$ & $1,4 \%$ \\
\hline 5 & 59 y 60 & $\begin{array}{l}\text { esparcimiento, culturales, } \\
\text { deportivos y otros servicios } \\
\text { de no mercado }\end{array}$ & $2,0 \%$ & $1,9 \%$ \\
\hline
\end{tabular}

Fuente: cálculos propios. Vector DIAN cálculos propios basados en la información F1007 año 2010. Vector DANE tomado de la página WEB DANE - Cuentas Nacionales-Anuales Matriz de Oferta 2010.

Tabla 14. Divisiones con mayor diferencia de participación en la oferta DIAN-DANE

\begin{tabular}{|c|c|c|c|c|}
\hline Top & División & Descripción división & $\begin{array}{c}\text { DANE } \\
\text { Participación oferta }\end{array}$ & $\begin{array}{c}\text { DIAN } \\
\text { Participación oferta }\end{array}$ \\
\hline 1 & 43 & Comercio & $0,00 \%$ & $22,38 \%$ \\
\hline 2 & 51 & $\begin{array}{l}\text { Servicios de intermediación } \\
\text { financiera, de seguros y } \\
\text { servicios conexos }\end{array}$ & $4,36 \%$ & $18,46 \%$ \\
\hline 3 & 52 & $\begin{array}{l}\text { Servicios inmobiliarios y de } \\
\text { alquiler de vivienda }\end{array}$ & $5,06 \%$ & $0,44 \%$ \\
\hline 4 & 45 & $\begin{array}{l}\text { Servicios de alojamiento, } \\
\text { suministro de comidas y } \\
\text { bebidas }\end{array}$ & $3,88 \%$ & $0,43 \%$ \\
\hline 5 & 27 & $\begin{array}{l}\text { Productos de la refinación } \\
\text { del petróleo; combustible } \\
\text { nuclear }\end{array}$ & $3,48 \%$ & $0,14 \%$ \\
\hline
\end{tabular}




\begin{tabular}{|c|c|c|c|c|}
\hline Top & División & Descripción división & $\begin{array}{c}\text { DANE } \\
\text { Participación oferta }\end{array}$ & $\begin{array}{c}\text { DIAN } \\
\text { Participación oferta }\end{array}$ \\
\hline 6 & 4142 & $\begin{array}{l}\text { Trabajos de construcción, } \\
\text { construcción de obras civiles } \\
\text { y servicios de arrendamien- } \\
\text { to de equipo con operario }\end{array}$ & $7,70 \%$ & $4,52 \%$ \\
\hline 7 & 54 & $\begin{array}{l}\text { Administración pública y } \\
\text { defensa; dirección, adminis- } \\
\text { tración y control del sistema } \\
\text { de seguridad social }\end{array}$ & $5,01 \%$ & $7,30 \%$ \\
\hline 8 & 2 & Otros productos agrícolas & $3,17 \%$ & $1,10 \%$ \\
\hline 9 & 28 & $\begin{array}{l}\text { Sustancias y productos } \\
\text { químicos }\end{array}$ & $5,05 \%$ & $3,06 \%$ \\
\hline 10 & 57 & $\begin{array}{l}\text { Servicios sociales y de salud } \\
\text { de mercado }\end{array}$ & $2,89 \%$ & $0,91 \%$ \\
\hline
\end{tabular}

Fuente: cálculos propios. Vector DIAN cálculos propios basados en la información F1007 año 2010. Vector DANE tomado de la página WEB DANE - Cuentas Nacionales-Anuales Matriz de Oferta 2010.

\section{Comparación de los vectores de oferta}

De manera similar a la comparación de la oferta, en la mayor parte de las divisiones, los valores de utilización del DANE están por encima de los valores calculados con la información de la DIAN; no obstante, en total es mayor la utilización calculada con la información de la DIAN (\$518.019 miles de millones) frente al resultado DANE (\$421.724 miles de millones) (ver anexo 2).

De la información anterior se evidencia lo siguiente:

i) En las cuentas del DANE, las divisiones de comercio, administración pública y servicios de enseñanza (No. 43, 54 y 56) no presentan valor de utilización de la producción. Por lo tanto, presentan una diferencias de 109.563 miles de millones de pesos con respecto a la cifras de la DIAN.

ii) Aquellas divisiones en cuya descripción se encuentran servicios de intermediación financiera y trabajos de construcción encontramos que los valores de utilización DIAN son mayores que los del DANE. Esto se debe a que la producción se define como un conjunto de productos, dejando los servicios fuera de las cuentas.

iii) En la división de hidrocarburos petróleo crudo, gas natural y minerales de uranio y torio, se presenta un margen de 11.208 miles de millones de diferencia entre DIAN y DANE.

El gráfico 14 contiene en el eje X la participación de las divisiones en la utilización total con los cálculos DIAN, y en el eje Y la participación de las divisiones en la utilización total con los cálculos del DANE. Se espera que si estas dos metodologías miden de manera 
equivalente la participación de la división j en el total de la utilización, el modelo de regresión lineal simple que pasa por el origen sea el de mejor ajuste, al ser coincidentes las parejas de los ejes. Bajo esta premisa podemos concluir que de la comparación de los vectores se encuentra que DIAN y DANE son cercanos en los vectores de utilización, en el gráfico 14 se señala los puntos cercanos al origen que estarían indicado participaciones DIAN-DANE numéricamente cercanas. Aquellos puntos que están más cercanos a la recta del gráfico 14, corresponden a las divisiones de bebidas, agua, productos de tabaco, gas domiciliario y servicios de enseñanza de no mercado, cuya participación en la oferta es la mejor estimada con la información DIAN (ver tabla 15); de otro lado las divisiones más alejadas del punto de origen corresponden a aquellas que presentan mayor diferencia en la información de las dos fuentes.

Gráfico 14. Comparación participación de la Utilización DIAN-DANE

\section{ESTRUTURA DE LA UTILIZACIÓN}

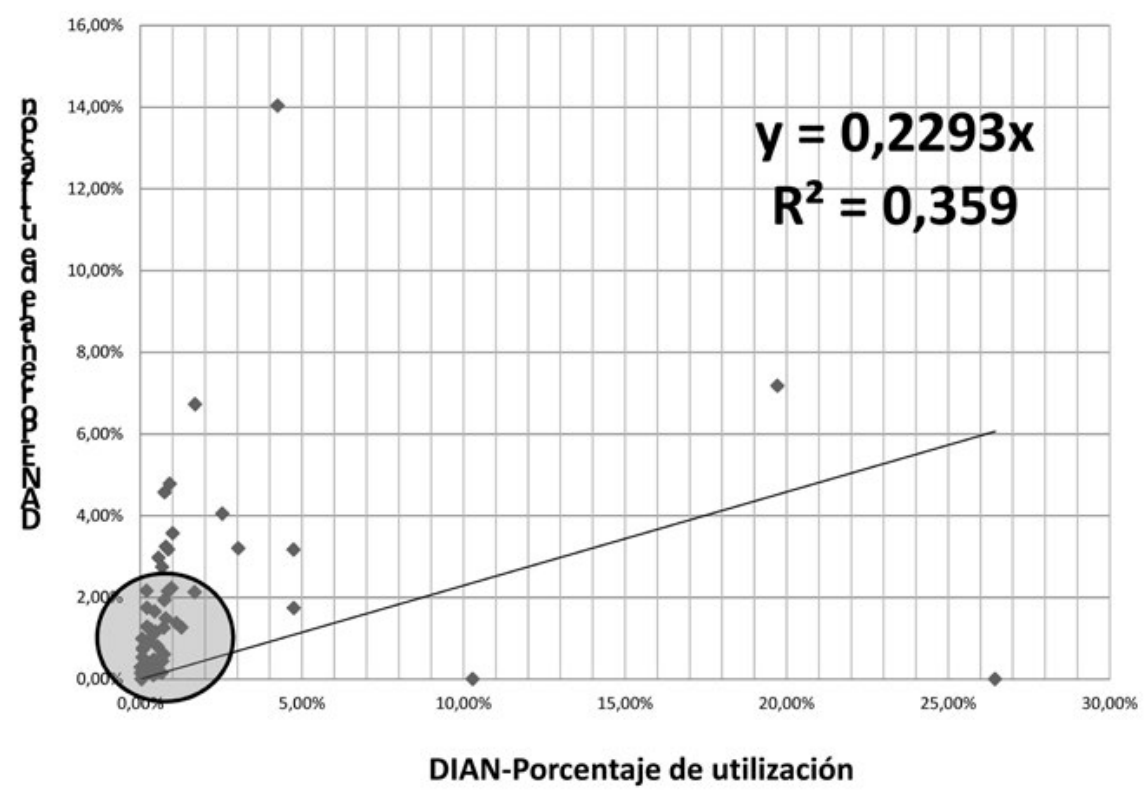

Fuente: vector DIAN cálculos propios basados en la información F1007 año 2010.

Vector DANE tomado de la página WEB DANE - Guentas Nacionales-Anuales Matriz de Oferta 2010. 
Tabla 15. Divisiones con participación similar de Utilización DIAN-DANE

\begin{tabular}{|c|c|l|c|c|}
\hline Top & División & \multicolumn{1}{|c|}{ Descripción división } & $\begin{array}{c}\text { DANE } \\
\text { Participación } \\
\text { utilización }\end{array}$ & $\begin{array}{c}\text { DIAN } \\
\text { Participación } \\
\text { utilización }\end{array}$ \\
\hline 1 & 18 & Bebidas & $1,27 \%$ & $1,28 \%$ \\
\hline 2 & 40 & Agua & $0,28 \%$ & $0,29 \%$ \\
\hline 3 & 19 & Productos de tabaco & $0,00 \%$ & $0,04 \%$ \\
\hline 4 & 39 & Gas domiciliario & $0,47 \%$ & $0,43 \%$ \\
\hline 5 & 56 & $\begin{array}{l}\text { Servicios de enseñanza de no mer- } \\
\text { cado }\end{array}$ & $0,00 \%$ & $0,05 \%$ \\
\hline
\end{tabular}

Fuente: cálculos propios. Vector DIAN cálculos propios basados en la información F1007 año 2010. Vector DANE tomado de la página WEB DANE - Cuentas Nacionales- Anuales Matriz de Utilización 2010.

Tabla 16. Divisiones con mayor diferencia de participación en la utilización DIAN-DANE

\begin{tabular}{|c|c|c|c|c|}
\hline Top & División & Descripción división & $\begin{array}{c}\text { DANE } \\
\text { Participación } \\
\text { utilización }\end{array}$ & $\begin{array}{c}\text { DIAN } \\
\text { Participación } \\
\text { utilización }\end{array}$ \\
\hline 1 & 43 & Comercio & $0,00 \%$ & $26,45 \%$ \\
\hline 2 & 51 & $\begin{array}{l}\text { Servicios de intermediación } \\
\text { financiera, de seguros y servicios } \\
\text { conexos }\end{array}$ & $7,18 \%$ & $19,72 \%$ \\
\hline 3 & 54 & $\begin{array}{l}\text { Administración pública y defensa; } \\
\text { dirección, administración y control } \\
\text { del sistema de seguridad social }\end{array}$ & $0,00 \%$ & $10,29 \%$ \\
\hline 4 & 53 & $\begin{array}{l}\text { Servicios a las empresas excepto } \\
\text { servicios financieros e inmobiliarios }\end{array}$ & $14,03 \%$ & $4,25 \%$ \\
\hline 5 & 28 & Sustancias y productos químicos & $6,72 \%$ & $1,70 \%$ \\
\hline 6 & 27 & $\begin{array}{l}\text { Productos de la refinación del } \\
\text { petróleo; combustible nuclear }\end{array}$ & $4,78 \%$ & $0,91 \%$ \\
\hline 7 & 31 & $\begin{array}{l}\text { Productos metalúrgicos básicos } \\
\text { (excepto maquinaria y equipo) }\end{array}$ & $4,57 \%$ & $0,75 \%$ \\
\hline 8 & 4142 & $\begin{array}{l}\text { Trabajos de construcción, } \\
\text { construcción de obras civiles y } \\
\text { servicios de arrendamiento de } \\
\text { equipo con operario }\end{array}$ & $1,74 \%$ & $4,75 \%$ \\
\hline 9 & 3 & $\begin{array}{l}\text { Animales vivos, productos animales } \\
\text { y productos de la caza }\end{array}$ & $3,57 \%$ & $1,00 \%$ \\
\hline 10 & 30 & Productos minerales no metálicos & $3,24 \%$ & $0,79 \%$ \\
\hline
\end{tabular}

Fuente: cálculos propios. Vector DIAN cálculos propios basados en la información F1007 año 2010.

Vector DANE tomado de la página WEB DANE - Cuentas Nacionales-Anuales Matriz de Utilización 2010. 